\title{
Rationale and design of the Sodium Lowering In Dialysate (SoLID) trial: a randomised controlled trial of low versus standard dialysate sodium concentration during hemodialysis for regression of left ventricular mass
}

Joanna Leigh Dunlop ${ }^{1,2}$, Alain Charles Vandal ${ }^{3}$, Janak Rashme de Zoysa ${ }^{4}$, Ruvin Sampath Gabriel ${ }^{5}$, Imad Adbi Haloob ${ }^{6}$, Christopher John Hood ${ }^{2}$, Philip James Matheson? ${ }^{7}$, David Owen Ross McGregor ${ }^{8}$, Kannaiyan Samuel Rabindranath ${ }^{9}$, David John Semple ${ }^{6}$ and Mark Roger Marshall ${ }^{1,2^{*}}$

\begin{abstract}
Background: The current literature recognises that left ventricular hypertrophy makes a key contribution to the high rate of premature cardiovascular mortality in dialysis patients. Determining how we might intervene to ameliorate left ventricular hypertrophy in dialysis populations has become a research priority. Reducing sodium exposure through lower dialysate sodium may be a promising intervention in this regard. However there is clinical equipoise around this intervention because the benefit has not yet been demonstrated in a robust prospective clinical trial, and several observational studies have suggested sodium lowering interventions may be deleterious in some dialysis patients.

Methods/design: The Sodium Lowering in Dialysate (SoLID) study is funded by the Health Research Council of New Zealand. It is a multi-centre, prospective, randomised, single-blind (outcomes assessor), controlled parallel assignment 3-year clinical trial. The SoLID study is designed to study what impact low dialysate sodium has upon cardiovascular risk in dialysis patients. The study intends to enrol 118 home hemodialysis patients from 6 sites in New Zealand over 24 months and follow up each participant over 12 months. Key exclusion criteria are: patients who dialyse more frequently than 3.5 times per week, pre-dialysis serum sodium of $<135 \mathrm{mM}$, and maintenance hemodiafiltration. In addition, some medical conditions, treatments or participation in other dialysis trials, which contraindicate the SoLID study intervention or confound its effects, will be exclusion criteria. The intervention and control groups will be dialysed using dialysate sodium $135 \mathrm{mM}$ and $140 \mathrm{mM}$ respectively, for 12 months. The primary outcome measure is left ventricular mass index, as measured by cardiac magnetic resonance imaging, after 12 months of intervention. Eleven or more secondary outcomes will be studied in an attempt to better understand the physiologic and clinical mechanisms by which lower dialysate sodium alters the primary end point.

(Continued on next page)
\end{abstract}

\footnotetext{
* Correspondence: mrmarsh@woosh.co.nz

'South Auckland Clinical School, Faculty of Medical and Health Sciences, University of Auckland, Private Bag 93311. Otahuhu, Auckland 1640, New Zealand

${ }^{2}$ Department of Renal Medicine, Middlemore Hospital, Counties Manukau District Health Board, Private Bag 93311, Otahuhu, Auckland 1640, New Zealand

Full list of author information is available at the end of the article
}

\section{Biomed Central}

(c) 2013 Dunlop et al.; licensee BioMed Central Ltd. This is an Open Access article distributed under the terms of the Creative Commons Attribution License (http://creativecommons.org/licenses/by/2.0), which permits unrestricted use, distribution, and reproduction in any medium, provided the original work is properly cited. 
(Continued from previous page)

Discussion: The SoLID study is designed to clarify the effect of low dialysate sodium upon the cardiovascular outcomes of dialysis patients. The study results will provide much needed information about the efficacy of a cost effective, economically sustainable solution to a condition which is curtailing the lives of so many dialysis patients.

Trial registration: Australian and New Zealand Clinical Trials Registry number: ACTRN12611000975998

Keywords: Home hemodialysis, Dialysis, Left ventricular mass, Sodium, Blood pressure, Fluid overload, Dialysate

\section{Background}

Dialysis is the world's most utilized modality of renal replacement therapy [1], and enables patients with end stage kidney disease (ESKD) to avoid imminently fatal complications such as hyperkalemia, acidosis, and pulmonary edema and thereby live longer. However, it is apparent that those on dialysis continue to have a uremic toxicity as manifested by a high rate of premature mortality. As is the case in other countries, the median survival of dialysis patients in New Zealand is approximately 4 years, with an overall mortality rate several-fold higher than that of the general population (Figure 1) [2]. This situation is largely attributable to premature cardiovascular $(\mathrm{CV})$ death, with infection playing the next most important role. Although not commonly appreciated, the patients with the highest proportion of CV deaths are those on home hemodialysis (HD), probably as a result of a lower competing risk of infectious death due to patient selection and reduced exposure to nosocomial pathogens. In Australia and New Zealand, $67 \%$ of patients on home HD die from CV disease [3].

The mechanism of $\mathrm{CV}$ death in dialysis patients appears to be different from that in the general population. Sudden cardiac death (SCD) due to lethal arrhythmia accounts for approximately half of $\mathrm{CV}$ deaths in the general population, and is most often a manifestation of coronary heart disease [4]. In contrast, SCD accounts for the majority of $\mathrm{CV}$ deaths in dialysis patients and is probably less likely due to sudden coronary ischemia [5,6]. More likely, arrhythmogenesis is triggered by re-entry pathways that are superimposed upon the usual ventricular conducting system by inter-myocardial cell fibrosis [7-9]. This fibrosis results from a synergy between left ventricular (LV) hypertrophy and uremia per se [10,11], and also contributes to a stiff and impaired myocardium and ultimately congestive heart failure [12-16].

There is a range of clinical evidence that supports the crucial role of for LV hypertrophy in SCD among dialysis patients. In a multitude of studies, the presence of LV hypertrophy is a strong independent mortality risk. In a landmark study, LV hypertrophy was associated with a relative risk for death of 2.9, even when adjusted for age, known coronary artery disease, diabetes, and blood pressure (BP) [17]. Of equal importance, recent studies have demonstrated that that the effect of lipid lowering therapy is attenuated in patients with kidney disease, reinforcing the lesser role of sudden rupture of lipid rich plaques as a mechanism of SCD in this group [18-21].

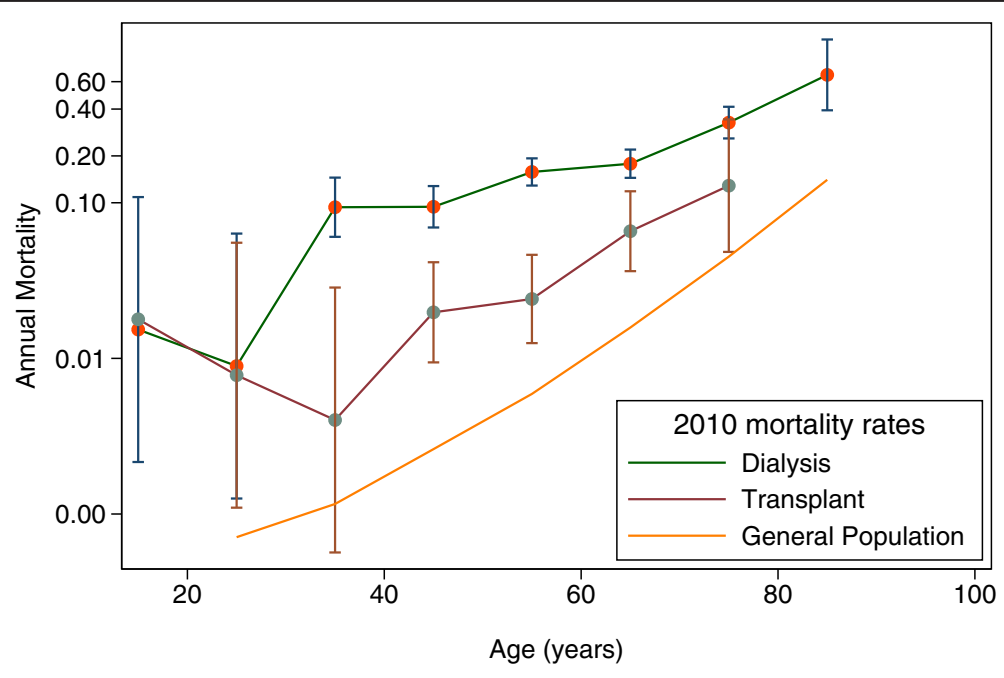

Source: ANZDATA Regsitry, Statistics New Zealand

Figure 1 Mortality in New Zealand patients treated by dialysis and transplantation during 2010 compared to the New Zealand general population. 
On balance, LV hypertrophy is regarded as a prime and causal risk factor for SCD, and the regression of LV hypertrophy accepted as a validated surrogate primary end point for interventions aiming to reduce CV mortality in dialysis patients [12,22,23].

Persistently elevated blood pressure (BP) and extracellular fluid (ECF) overload due to positive salt and water balance are significant contributors to on-going LV hypertrophy with conventional (non-extended-hours) dialysis [24-33]. Current methods to control these factors with either drug therapy or ultra-filtration in patients on conventional dialysis can be effective but are often inadequate in routine clinical practice [27,34-38]. The most effective intervention to improve LV hypertrophy is extended-hours or frequent HD. A randomised controlled trial of extended-hours HD demonstrated a $7.7 \%$ reduction in LV mass over a 6month period for patients dialysed in this manner, as opposed to a stable LV mass in those dialysed conventionally [35]. Similar findings were published in the Frequent Haemodialysis Network trial [34]. In both studies, regression of LV mass was associated with improved measures of BP and ECF volume control. Several observational studies have reported similar findings [39,40].

Not all patients, however, are able to manage extended-hours or frequent HD and not all health systems are able to deliver such programs. A more accessible alternative may be available in reducing sodium exposure through lower dialysate $[\mathrm{Na}+]$. Sodium loading by either excessive dietary intake or excessive diffusion via dialysate has been shown to increase both BP and intradialytic weight gain (IDWG) [41]. Moreover, elevation in plasma $[\mathrm{Na}+]$ can induce hypertension independently of EC fluid volume, through mechanisms that probably include stiffening of vascular endothelium [42-46]. A number of observational studies as well as small and often uncontrolled clinical studies have shown that lower dialysate $[\mathrm{Na}+]$ associates with less thirst [47-55], lower IDWG $[48,49,51-53,56-78]$, lower ECF volume [66,76,79,80], and lower BP $[48,51,54,56,61-69,75,81-83]$, with only a minority of studies being completely negative $[47,77,84-88]$. A typical example can be found in preliminary research by the SoLID trial research team, who previously showed that a decrease in dialysate $[\mathrm{Na}+]$ by $3 \mathrm{mM}$ in 52 facility based patients was well tolerated and reduced systolic and diastolic BP by $4-5$ and $2-3 \mathrm{mmHg}$, respectively [89]. Improvement in intermediary outcomes such as BP suggest that lower dialysate $[\mathrm{Na}+]$ could be beneficial for improving LV hypertrophy as well. There have been only two studies examining the effect of lower dialysate $[\mathrm{Na}+]$ on LV structure and function [90,91]. One study reported an associated decrease in LV volumes, although both were too brief to assess for changes in LV mass.
However, the potential benefits of lower dialysate $[\mathrm{Na}+]$ should be weighed against a potential "dark side". Several large and well performed observational analyses have shown an association between lower dialysate $[\mathrm{Na}+]$ and higher mortality risk, notably in those patients with a "frail" phenotype characterized by low serum $[\mathrm{Na}+]$, diabetes mellitus, coronary artery disease, $\mathrm{CV}$ disease, congestive heart failure, cerebrovascular disease, lung disease, and cancer $[72,92,93]$. The most plausible explanation for these observations relates to decreased hemodynamic stability with lower dialysate $[\mathrm{Na}+]$, and the vulnerability of "frail" patients to intra-dialytic hypotension, an unquestionably threatening condition associated with myocardial stunning and all-cause patient mortality [94-99]. Intra-dialytic hypotension is ameliorated by higher dialysate $[\mathrm{Na}+]$, and is likely to be at least as deleterious (if not more so) as inter-dialytic hypertension.

Another concern with lower dialysate $[\mathrm{Na}+]$ is that it might influence serum $[\mathrm{Na}+]$. Humans are considered to have an individual natremic set point, and most observational studies have not shown any cross-sectional correlation between dialysate and serum [Na+] [67,73,100-105]. However, pre-dialysis serum $[\mathrm{Na}+]$ did change in several small prospective clinical trials after changes to dialysate [Na+] [54,58,62,64,89,106,107], albeit often after a lag of several months possibly due to the large reservoirs of non-osmotic sodium in skin and bone [108-111]. There is a clear association between low serum $[\mathrm{Na}+]$ and patient mortality in patients with kidney disease, and an intervention that might potentially lower serum $[\mathrm{Na}+]$ warrants careful scrutiny [112-114].

A final concern is raised by clinical trials of dietary salt reduction in non-ESKD populations. Overall, there is higher mortality and morbidity in those participants who had the lowest salt intake, especially in the setting of generally low salt consumption [115-117]. A number of plausible biological mechanisms might be contributing to the poorer outcomes among those with low salt intake, involving several key metabolic and neurohormonal pathways (e.g. activation of sympathetic nervous and renin-angiotensin systems, increased in total and low-density lipoprotein cholesterol, reduction in peripheral insulin sensitivity etc.) [118-121].

Overall, there is clinical equipoise around lower dialysate $[\mathrm{Na}+]$ due to the multiple physiological consequences of reducing salt exposure in this population, and the uncertain net effect on CV outcomes as a result of these often competing and often conflicting physiological responses (Figure 2) [41]. The SOdium Lowering In Dialysate (SoLID) trial has been designed to answer the following clinical question: Does lower dialysate $[\mathrm{Na}+]$ improve $\mathrm{CV}$ mortality risk compared to conventional dialysate $[\mathrm{Na}+]$, in prevalent home HD patients who are exposed over a duration of a year? The research 


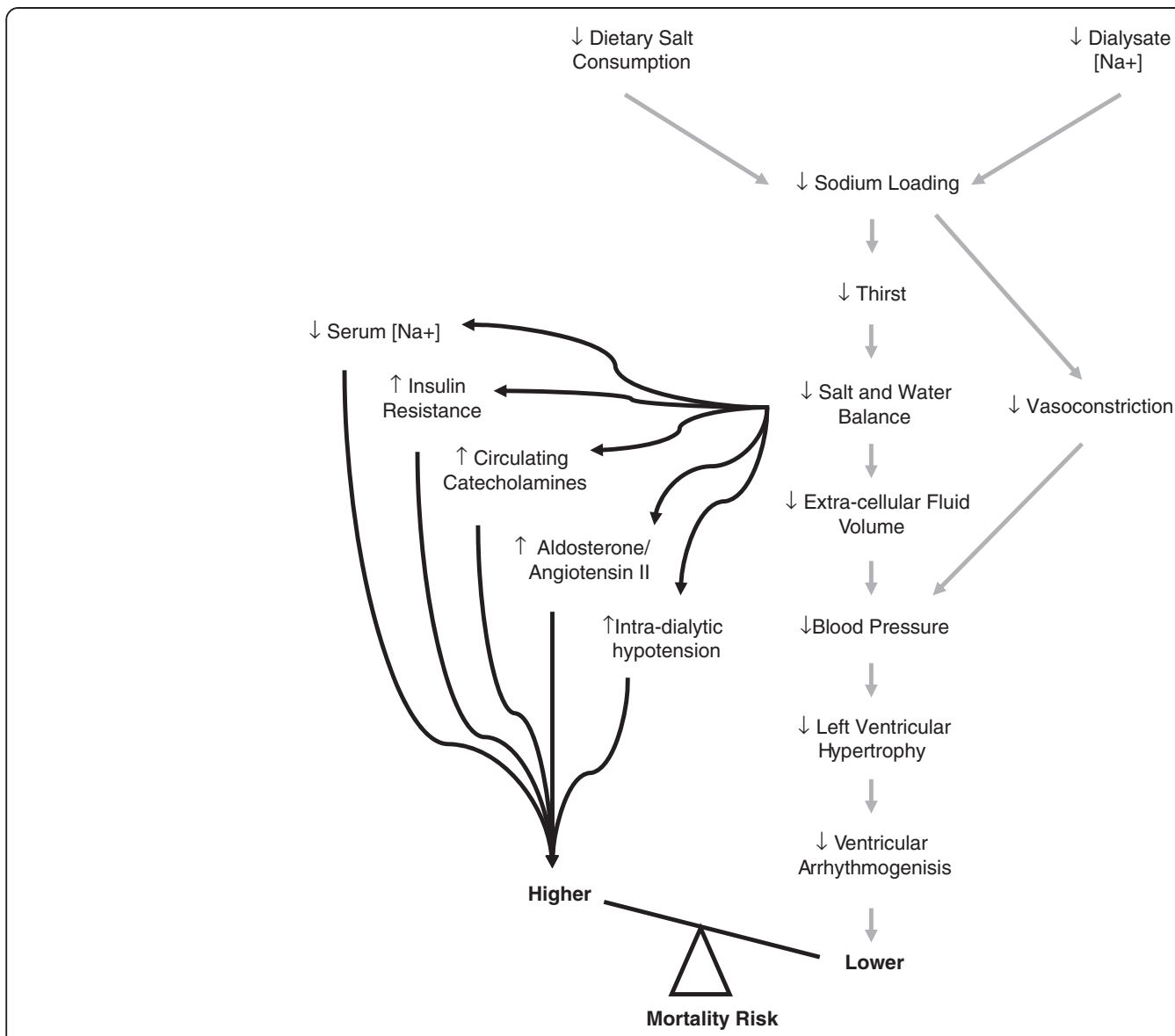

Figure 2 Causal diagram relating low salt exposure during hemodialysis to cardiovascular mortality risk (reproduced with permission from Marshall and Dunlop [41]).

aims to address the clinical question through a randomised controlled trial of low versus standard dialysate $[\mathrm{Na}+]$, while observing the effect of allocation and exposure upon participant's LV mass, an accepted surrogate outcome for $\mathrm{CV}$ mortality in end-stage kidney disease populations [12,22,23,36,122].

\section{Methods/design}

\section{Study aim and hypothesis}

The aim of this research is to examine the impact of low dialysate $[\mathrm{Na}+]$ on cardiovascular risk in patients on dialysis. Our primary hypothesis is that low dialysate $[\mathrm{Na}+]$ for one year among patients undergoing home HD will result in reduced LV mass. Our secondary hypothesis is that low dialysate $[\mathrm{Na}+]$ will also result in the following outcomes compared to conventional dialysate $[\mathrm{Na}+]$ : improved markers of thirst; better control of BP and markers of ECF volume; improved LV volumes and hemodynamics; decreased arterial stiffness; improved markers on long term $\mathrm{CV}$ mortality risk; non-inferior tolerance to dialysis; noninferior plasma $\mathrm{Na}+$ ionic activity and osmolarity; and non-inferior health-related quality of life.

\section{Study design and setting}

The SoLID trial is a multi-centre prospective, randomised, single-blind (outcomes assessor), controlled, parallel assignment 3-year clinical trial (Figure 3). There will be accrual of participants over 24 months, and a follow up duration of 12 months. Participants will be randomly allocated to either low dialysate $[\mathrm{Na}+]$ of $135 \mathrm{mM}$ or conventional dialysate $[\mathrm{Na}+]$ of $140 \mathrm{mM}$ for 12 months duration, interventions that represent poles of customary practice with respect to dialysate $[\mathrm{Na}+]$ prescription in New Zealand. The trial will be conducted within 6 of the country's 20 District Health Boards (DHBs), which are entities responsible for the provision of governmentfunded health and disability services in their geographical district. All of the DHBs in the SoLID trial provide renal services and have comprehensive home HD programmes: Counties Manukau, Waitemata, Auckland, Capital \& Coast, and Canterbury. Participants will be either predominantly from urban settings (Counties Manukau, Waitemata and Auckland DHBs) or from a mixture of urban and rural ones (Capital \& Coast, Canterbury, Waikato). For logistical reasons, no participant will be 


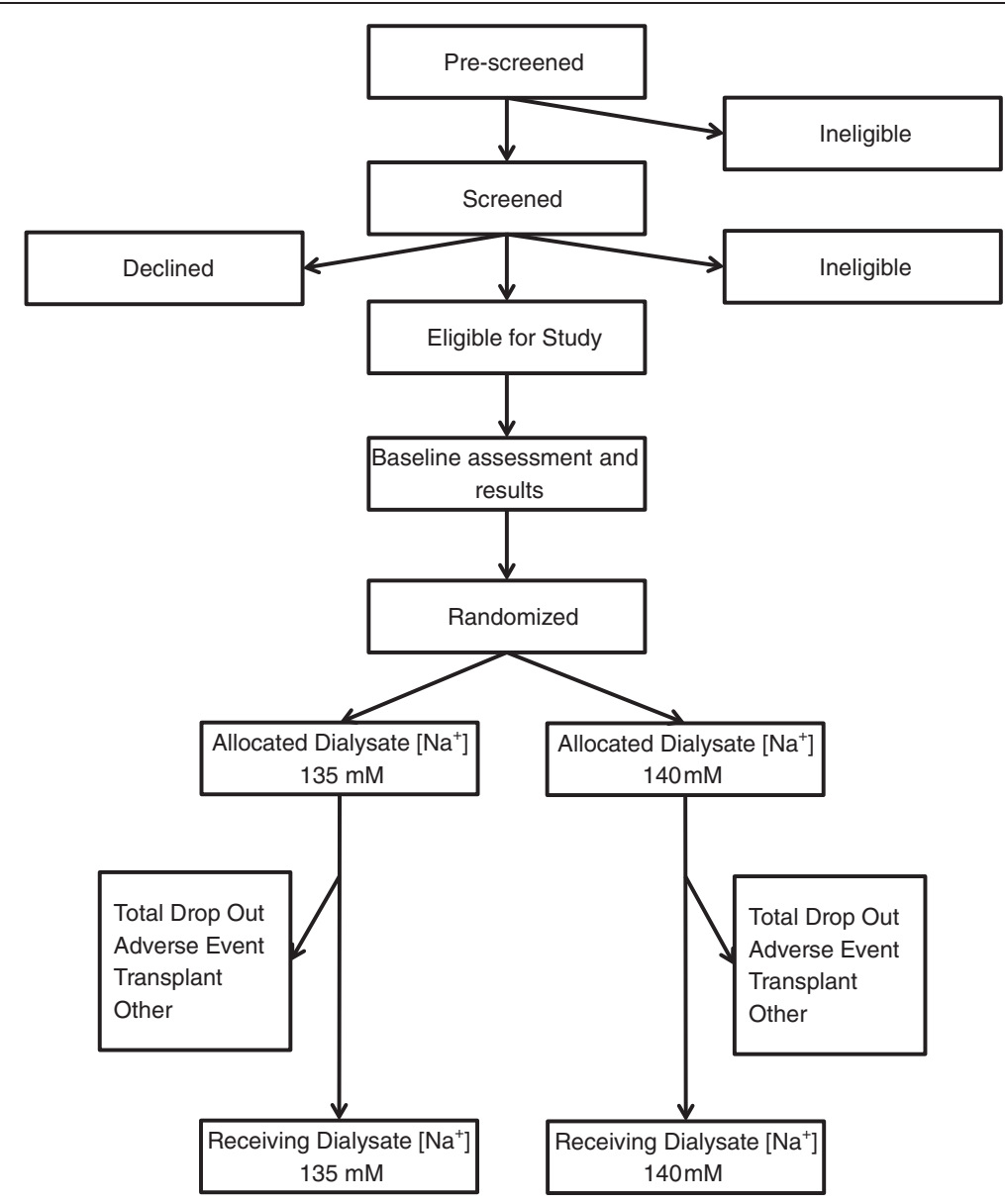

Figure 3 The SoLID trial participant flowchart.

enrolled who lives more than 90-120 minutes from the hospital providing tertiary renal services.

\section{Ethical considerations}

Ethical approval has been obtained through the National (New Zealand) Multi-region Ethics Committee and each institutional review board within participating DHBs.

\section{Target population and eligibility criteria}

The target population will be patients with ESKD on home HD. The particular sampling frame for the SoLID trial is chosen because home HD patients have the large attributable risk of death from $\mathrm{CV}$ as opposed to other causes [3], and a less "frail" phenotype compared to those dialysing in facilities with less tendency to intradialytic hypotension [123,124]. They are also the least likely dialysis patients to suffer from other inter-current illnesses that might result in their death or drop out from the trial (Figure 4), and are probably more likely to be compliant with the study procedures.

Eligibility criteria will include incident or prevalent patients treated with maintenance home HD under the care of the 6 participating DHBs who are; aged 18 years or older; suitable for both low and standard dialysate $[\mathrm{Na}+]$ in the view of their treating physician; have predialysis plasma $[\mathrm{Na}+] \geq 135 \mathrm{mM}$; and are willing to participate and able to provide consent.

Exclusion criteria will include HD treatments at a frequency greater than 3.5 times per week; treatment with maintenance hemodiafiltration; life expectancy of less than 12 months; scheduled for live donor kidney transplantation within 12 months of entry to the study; considered by the treating nephrologist to have concomitant illnesses or conditions that limit or contraindicate study procedures and follow-up (e.g. frequent intra-dialytic hypotension requiring fluid resuscitation); considered by the treating nephrologist to have a high chance of nonadherence to study treatments and non-attendance for procedures and follow up; current enrolment in clinical studies involving anti-hypertensive medications, changes in HD operating parameters, or any other intervention that is likely to confound the outcome of the trial; currently using sodium profiling during haemodialysis treatments; documented infiltrative cardiomyopathies 


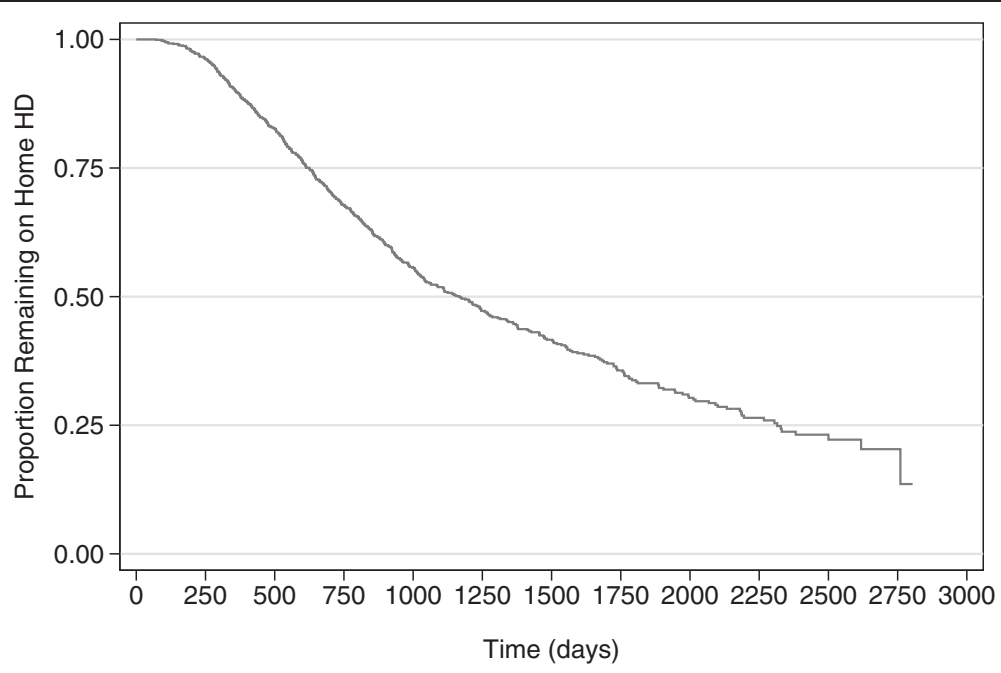

Figure 4 Kaplan-Meier estimates of non-death non-transplant censored home hemodialysis technique survival for the modern New Zealand population (2000-2010), from ANZDATA Registry; drop-out from home hemodialysis is $9.8 \%$ per year $(15.3 \%, 53.6 \%$, and $25.8 \%$ of drop-outs due to death, transplantation, and modality change respectively).

(amyloid, glycogen storage disease), hereditary cardiomyopathies (hypertrophic cardiomyopathy) or moderate to severe aortic valve disease (aortic stenosis, regurgitation); inability to provide consent or follow study instructions due to mental health illnesses or conditions.

\section{Recruitment of participants}

The research team at each site will utilise a purpose built pre-screening database in order to identify potential participants eligible for inclusion in the trial. Potential participants will then be approached by either their dialysis nurse, doctor or the trial research co-ordinator and formally invited to consider participation. After an initial explanation, we will provide further written information and schedule a follow-up meeting. At that meeting, potential participants will be able to meet the site investigator with a language interpreter as necessary, and ask any questions that arise from information that has provided. If the potential participant is willing to participate, they will provide written consent. Whenever a signed consent form is received from a patient they will be formally screened to confirm their eligibility and then enrolled in the trial. Patients who are approached but decline to participate or consent but are not eligible when screened will be recorded in a screening $\log$ and their care will continue in the usual fashion.

\section{Randomisation}

Once baseline assessments have been completed and 28 days have elapsed since enrolment onto the trial, randomisation will be performed using a phone based interactive voice response system (IVRS) from the National (Australia) Health Medical Research Council (NHMRC),
Clinical Trials Centre (CTC) Sydney, Australia. Participants will be randomised in computer generated blocks of random size (undisclosed), blinded to investigators, and stratified by a) treating centre, and b) whether they receive conventional ( $\leq 18$ hours/week) or extended-hour (>18 hours/week) HD.

\section{Blinding}

Baseline data will be collected prior to randomisation so that trial investigators, research co-ordinators and trial participants will be blinded to allocation while the baseline data is being collected. However, blinding will be not be maintained once randomisation has occurred. Assessors for the primary outcome of the study will be blinded for the duration of the trial. Assessors for the secondary outcomes of the study will not be blinded.

\section{Interventions}

It has been previously estimated that high sodium exposure during HD for most populations would be characterized by dialysate $[\mathrm{Na}+]$ of $\sim 141 \mathrm{mM}$, and low sodium exposure by dialysate $[\mathrm{Na}+]$ of $\sim 135 \mathrm{mM}[101]$. Increasingly, there are calls by opinion leaders for individualised dialysate $[\mathrm{Na}+]$ prescriptions as being the most physiological approach to manage sodium balance. Individualised prescriptions can be achieved through the automated application of sodium kinetic (or conductivity) models, or the manual application of simplified algorithms based on patient pre-dialysis [Na+] [102,125-131]. However, preliminary research by the SoLID research team has suggested that natremic adaptation may in fact occur over time in response to altered dialysate [Na+] [89]. Moreover, there is no evidence that the results achieved using 
individualised dialysate $[\mathrm{Na}+]$ prescriptions are better than those achieved with the simpler and less expensive intervention of a fixed lower dialysate $[\mathrm{Na}+]$ applied to everyone. Consequently, dialysate $[\mathrm{Na}+]$ in our study arms will be fixed rather than individualised for all participants. A 2010 poll of dialysate $[\mathrm{Na}+]$ by the SoLID research team has shown that the median setting for the New Zealand centres was $139 \mathrm{mM}$.

Low Dialysate $[\mathrm{Na}+]$ : This group will undergo home HD with dialysate $[\mathrm{Na}+]$ of $135 \mathrm{mM}$ for a duration of one year, introduced gradually by decrements of $1 \mathrm{mM} /$ week over a 4-8 week run-in period as necessary. BP will be optimized by changes to target weight and antihypertensive medications according to a standardized protocol.

Standard Dialysate $[\mathrm{Na}+]$ : This group will undergo home $\mathrm{HD}$ with dialysate $[\mathrm{Na}+]$ of $140 \mathrm{mM}$ for a duration of one year, similarly introduced by changes of $1 \mathrm{mM} /$ week over an appropriate run-in period. BP will be optimised in an identical manner as above.

In the event of titration failure, the dialysate $[\mathrm{Na}+]$ level reached while aiming for the target level will be retained for the remainder of the follow-up, although such cases will be classified as being protocol violations.

Apart from dialysate $[\mathrm{Na}+]$, HD operating parameters for all participants will be managed in usual fashion according to local treatment goals. Dietary salt intake will be managed in all participants according local clinical practice guidelines [132], and monitored at baseline, 6months and 12 months using 3-day food diaries and analyses with Foodworks Pro $^{\circ} 9.0$ (Xyris Software, Brisbane, Australia). Urinary Na+excretion will be monitored in all participants at baseline, 6 months and one year follow-up using inter-dialytic urine collection.

\section{Research outcomes and endpoints}

The schedule of SoLID trial investigations and visits are summarised in Table 1, and outcomes are described below.

\section{Primary outcome - LV mass index}

The primary outcome measure of the SoLID trial is LV mass index (LVMI), and the primary endpoint is LVMI at 12 months. LVMI is also measured at baseline. LVMI will be measured using cardiac magnetic resonance imaging (MRI) imaging performed prior to HD treatments after a "long break" (the longest HD-free interval in any rolling schedule) or mid-week for participants who have fixed inter-dialytic intervals. All cardiac MRI scans will be performed at the local sites using a standardised protocol. Assessment of LV function will be performed using trueFISP cine imaging (6-7 short axis and 3 LV long axis with 20-30 cardiac phases depending on heart rate). Analysis of the images will be performed at a core laboratory at the Auckland MRI Research
Group, University of Auckland, New Zealand. Each patient will have a four-dimensional mathematical model of the left ventricle created using guidepoint fitting. In all cases, volume, mass and wall thickness will be measured directly from the moving 3D curved surfaces which track the motion of the endo- and epicardium. This method has been validated for global parameters such as LV mass, end-diastolic volume, end-systolic volume, stroke volume and ejection fraction using global gold standard models [133]. All data will be analysed in duplicate by two independent and blinded analysts and the results reconciled in accordance with standard operating procedures of the group. Analysts will be monitored weekly for drift.

\section{Secondary outcomes}

LV volumes LV volumes will be measured by cardiac MRI at baseline, and the endpoint will consist of followup measurements at 12 months. Measurements will be made used the same methodology used for LV mass index.

LV hemodynamics LV hemodynamics will be as assessed by NT-pro-BNP (N-terminal pro brain natriuretic peptide) [134-140] and Urotensin II levels [141-145]. Measurements will be made at baseline, and the endpoints will consist of measurements at 3, 6, 9 and 12 months. All blood samples will be taken immediately prior to HD treatment following a "long break" or midweek for participants who have fixed inter-dialytic intervals. All measurements will be made by the Christ church Cardiac Endocrine group in Christ church, New Zealand using the Elecsys ${ }^{\circ}$ ProBNP assay (Roche Diagnostics Corporation, Indianapolis, IN, USA) and an in-house radioimmune assay for Urotensin II [146].

Extracellular fluid volume ECF volume will be assessed by bioimpedance spectroscopy [147-149]. Measurements will be made at baseline, and the endpoints will consist of measurements at 3, 6, 9 and 12 months. All assessments will be performed immediately prior to HD treatments after a "long break" or mid-week for participants who have fixed inter-dialytic intervals. All measurements will be made using the Fresenius BCM monitor ${ }^{\circ}$ (Fresenius Medical Care Australia Pty Ltd (New Zealand Branch), Auckland, New Zealand).

Blood pressure BP will be assessed in the following ways;

a. Intra-dialytic BP (including pre- and post-dialysis $\mathrm{BP})$. Measurements will be made at baseline, and the endpoints will consist of measurements at 3, 6, 9 and 12 months $[150,151]$. An additional endpoint 
Table 1 Schedule of participant investigations and visits

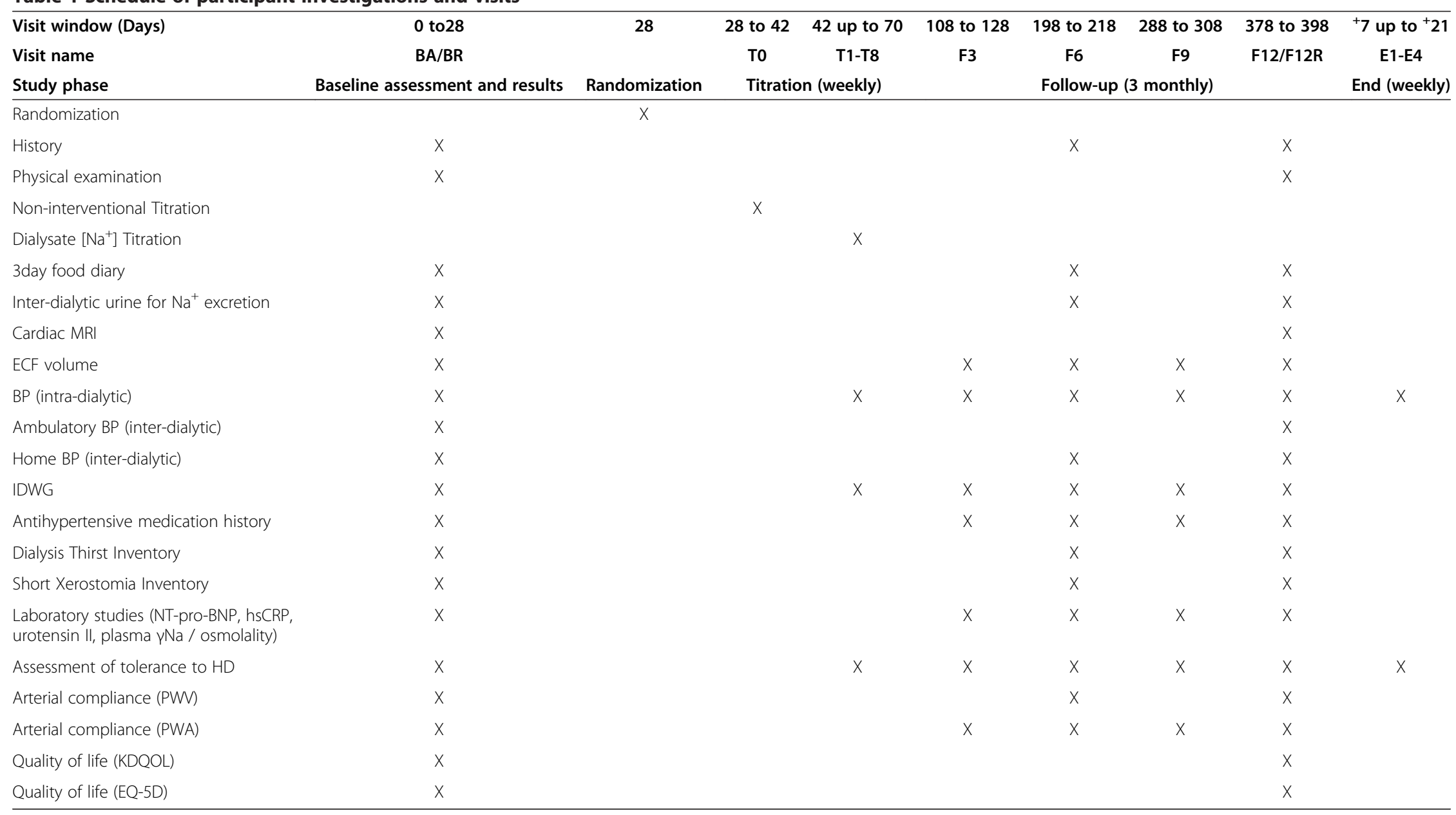


will consist in the intra-dialytic blood pressure timeaveraged over the individual follow-up period, using all available measurements accepting that there may be differing numbers of measurements per participant and time point.

b. Inter-dialytic BP assessed by the gold standard of ambulatory monitoring [150,152-155]. Measurement will be made at baseline, and the endpoint will consist of measurement at 12 months. All assessments will be performed according to the 'Practice Guidelines of the European Society of Hypertension' for clinic, ambulatory and self BP measurement [156]. Systolic and diastolic BP measurements will be made at 30 minute measurement intervals for 44 hours during a "long break" or mid-week for participants who have fixed inter-dialytic intervals. All measurements will be made using Oscar 2 ambulatory BP monitors (Suntech Medical Instruments, Raleigh, NC, USA). Measurements will be made on the non-access arm, and the measurement arm will be kept consistent during the study. Ambulatory BP monitoring will be considered adequate if at least two-thirds of the measurements taken over the 44-hour period are satisfactory [156].

c. Inter-dialytic BP determined as the weekly average of home blood pressure readings, an independently validated approach $[150,157,158]$. Measurements will be made at baseline, and the endpoints will consist of measurements at 6 and 12 months. Measurements will made using the Omron HEM791IT Blood Pressure Monitor (Omron Healthcare Inc, Lake Forest, IL, USA). Readings will be made 3 times per day (on waking up, between noon and 1900 , and before bed) during the 7 days immediately prior to 3, 6, 9 and 12 months [150,157,158].

$\mathrm{d}$. The number and dose of anti-hypertensive medications (expressed as the aggregated\% of maximum recommended daily dose) [159]. Measurements will be made at baseline, and the endpoints will consist of measurements at 3, 6, 9 and 12 months.

Inter-dialytic weight gain (IDWG) IDWG will be calculated by the difference between pre- and- post dialysis weight. Measurements will be made at baseline, and the endpoints will consist of measurements at 3, 6, 9 and 12 months. An additional endpoint will consist in the inter-dialytic weight gain time-averaged over the individual follow-up.

Thirst and xerostomia Thirst and xerostomia will be assessed by visual analogue scale using standardised validated inventories [160-163]. Measurements will be made at baseline, and the endpoints will consist of measurements at 3, 6, 9 and 12 months.

High sensitivity C-reactive protein (hsCRP) Long term CV mortality risk will be assessed by hsCRP [164]. Measurements will be made at baseline, and the endpoints will consist of measurements at 3, 6, 9 and 12 months. All blood samples will be taken immediately prior to HD treatment following a "long break" or mid-week for participants who have fixed inter-dialytic intervals. All measurements will be made using the Abbott Architect ${ }^{\circ}$ Analyser and CRP Vario $^{\circ}$ latex immunoassay (Abbott Park, IL, U.S.A).

Arterial compliance Arterial stiffness will be assessed by carotid-femoral Pulse Wave Velocity (PWV) and by radial Pulse Wave Analysis (PWA, deriving both central pulse pressure and the augmentation of the central pulse waveform at the radial artery). The methodology represents the current gold standard for non-invasive measurement of aortic arterial stiffness [165]. Pulse Wave Velocity measurements will be made at baseline, and the endpoints will consist of measurements at 3, 6, 9 and 12 months. Pulse Wave Analysis measurements will be made at baseline, and the endpoints will consist of measurements at 6 and 12 months. Assessments will be performed immediately prior to HD treatments after a "long break" or mid-week for participants who have fixed inter-dialytic intervals. Measurements will be made using the SphygmoCor ${ }^{\circ}$ device (AtCor Medical, West Ryde, Australia) which employs applanation tonometry to measure the shape and velocity of the pulse wave, with good repeatability and reproducibility. Both PWV and PWA measurements will be measured in duplicate. If the difference between the two PWV measurements is $>10 \%$, a third measurement will be performed and the average the two most similar measurements used. For quality control, the Sphygmocor calculates the standard deviation (SD) of the pulse transit time (PTT) over the 10 second waveform capture period. A carotid-femoral PTT SD of $<20 \%$ in dialysis patients is considered by the manufacturers to indicate a good quality measurement for PWV and will be the accepted maximum carotidfemoral PTT SD for measurements in this trial.

Pre-dialysis plasma sodium ionic activity $(\gamma \mathrm{Na})$ Predialysis plasma $\gamma \mathrm{Na}$ and osmolality will be assessed at baseline, and the endpoints will consist of measurements at 3, 6, 9 and 12 months. All blood samples will be taken immediately prior to HD treatment following a "long break" or mid-week for participants who have fixed inter-dialytic intervals. Plasma $\gamma \mathrm{Na}$ measurements will be made by direct inometry using an ABL800 or ABL83 blood gas analyser (Radiometer, Copenhagen, Denmark) 
and corrected by a factor of 0.967 to account for the Donan Effect from negatively charged plasma proteins [166]. Plasma osmolality will be analysed by freezing point depression using the Advanced $^{\circ}$ Model 3320 Micro-Osmometer (Advanced Instruments, Norwood, MA, USA).

Health related quality of life Consistent with previous recommendations [167-169], health related quality of life (HRQoL) will be assessed using a spectrum of validated instruments. Measurement will be made at baseline, and the endpoint will consist of measurement at 12 months. Measurements will be made using the Kidney Disease Quality of Life (KDQOL) [170-172] and the preference based EuroQol EQ-5D questionnaires [167,173].

\section{Tolerability outcome}

Tolerance to dialysis Tolerance to dialysis will be assessed by the frequency of intra-dialytic hypotension episodes in the two weeks prior to the assessment time point. Hypotension episodes will be identified according to the NKF-K/DOQI definition (a decrease in systolic BP by $\geq 20 \mathrm{mMHg}$ or a decrease in mean arterial pressure by $\geq 10 \mathrm{mMHg}$ associated with one or more of the following symptoms: abdominal discomfort, nausea, vomiting, muscle cramps, restlessness, dizziness, fainting, anxiety and the requirement for fluid boluses) [164]. Measurements will be made at baseline, and the endpoints will consist of measurements at 3, 6, 9 and 12 months. An additional tolerance endpoint will consist in the time-averaged frequency of hypotension episodes over the individual follow-up period.

\section{Monitoring for adverse events}

A formal Data Monitoring Committee (DMC) constituted by the New Zealand Health Research Council Data Monitoring Core Committee will monitor safety and trial conduct according to the terms of its charter. An independent study statistician and data manager will generate both the open and closed Reports for the $\mathrm{DMC}$, and have no connection to the clinical aspects of the trial. Because of power considerations and the fact that safety of low dialysate $[\mathrm{Na}+]$ was demonstrated in the pilot study, no interim analyses are planned and no stopping rule based on statistical significance of efficacy data, frequentist or Bayesian, has been set. However, safety reports will be made and reviewed by the DMC on a 6 monthly basis.

\section{Power calculation}

Power calculations are based on the primary outcome measure of LVMI. The SoLID trial assumes a baseline mean (standard deviation, SD) LVMI of 110 (40) g/m2, based on published data in HD populations using cardiac MRI [33,174,175]. The trial assumes a 12 month follow-up LVMI of 95 (35) $\mathrm{g} / \mathrm{m} 2$ in the low dialysate [Na+] group based on the change in LVMI observed over 6 months in clinical trials of frequent or nocturnal HD [27,34,35]. Correlation between baseline and 12-moth follow-up measurements of LVMI in the SoLID trial is assumed to be 0.75 based on private communication from the Jardine group (private communication P Mark 8/2/2011): in a cohort of 59 patients of their patients with repeated measures of LVMI at least 6 months apart (using cardiac MRI), correlation was $0.87(\mathrm{p}<0.001)$ with normally distributed data $[33,174,175]$. Modelling these data using repeated-measures analysis of covariance (ANCOVA), and allowing for $25 \%$ for drop outs, 59 participants will be enrolled in each arm (power 0.8, alpha $0.05)$. The SoLID trial will therefore enrol 118 trial participants over the 6 participating sites in NZ.

\section{Analysis populations}

For analysis of data, we define Intention to Treat (ITT) and Per Protocol (PP) populations. The ITT population consists of all randomised participants who have at least one baseline measurement, and is the primary population of interest. All randomised participants will be analysed in the group they were allocated to, even if they do not receive the allocated treatment, do not commence treatment, change dialysis modality, are lost to follow-up, or die thereby preserving the intention-totreat framework. In particular, titration failures will remain within the ITT population as participants.

The PP population consists of participants that fulfil criteria for the ITT population, have complete primary endpoint measurements and do not present any major protocol violations during the study. The following describes the major protocol deviations that will exclude patients from the PP population (minor deviations will not do so): eligibility violation; absence of any efficacy data, titration failure; other major violations will be identified by the $\mathrm{DMC}$ of the trial during the study and/or during the data review process. The list of all protocol deviations will be reviewed by the DMC who will determine the degree of the violation (i.e. major versus minor). All protocol deviations considered as minor will not lead to excluding patients from the PP population for analysis.

\section{Statistical analysis}

Primary and secondary subgroup and non-subgroup analyses are provided in Table 2. For statistical analyses, we define predictors, related to outcome and unrelated to the allocation; potential confounders, related to outcome and imbalanced by chance across the treatment arms; and potential effect modifiers, that may moderate the treatment arm effect. The former two are hereafter identified as potential covariates. 
Table 2 Primary and secondary analyses

\begin{tabular}{|c|c|c|c|c|}
\hline Analyses & Population & Subgroup & Endpoints & Framework \\
\hline Primary & $\mathrm{ITT}$ & None & Primary & Univariate \\
\hline \multirow[t]{9}{*}{ Secondary } & PP & None & Primary & Univariate \\
\hline & $\mathrm{ITT}$ & None & Secondary & Univariate \\
\hline & $\mathrm{ITT}$ & None & Secondary & Multivariate \\
\hline & $\mathrm{ITT}$ & $\begin{array}{l}\text { Baseline LVMI subgroups (observed } \\
\text { median LVMI as the level boundary) }\end{array}$ & Primary & Univariate \\
\hline & $\mathrm{ITT}$ & $\begin{array}{l}\text { Baseline LVMI subgroups (observed } \\
\text { median LVMI as the level boundary) }\end{array}$ & $\begin{array}{l}\text { Time-averaged blood pressure over } \\
\text { months } 3,6,9 \text { and } 12 \text { (intra-dialytic, } \\
\text { inter-dialytic), \% maximum recommended } \\
\text { daily dose of antihypertensives }\end{array}$ & $\begin{array}{l}\text { Multivariate, accounting for subgroup } \\
\text { effect and treatment-subgroup } \\
\text { interaction, FDR control to account } \\
\text { for multiplicity }\end{array}$ \\
\hline & $\mathrm{ITT}$ & $\begin{array}{l}\text { Baseline intra-dialytic and inter- } \\
\text { dialytic blood pressure subgroups } \\
\text { (observed mean blood pressure as } \\
\text { the level boundary) }\end{array}$ & Primary & $\begin{array}{l}\text { Univariate, accounting for subgroup } \\
\text { effect and treatment-subgroup } \\
\text { interaction, and three-way interaction }\end{array}$ \\
\hline & $\mathrm{ITT}$ & $\begin{array}{l}\text { Baseline intra-dialytic and inter- } \\
\text { dialytic blood pressure subgroups } \\
\text { (observed mean blood pressure as } \\
\text { the level boundary) }\end{array}$ & $\begin{array}{l}\text { Time-averaged blood pressure over } \\
\text { months 3, 6, } 9 \text { and } 12 \text { (intra-dialytic, } \\
\text { inter-dialytic), \% max recommended } \\
\text { daily dose of antihypertensives }\end{array}$ & $\begin{array}{l}\text { Univariate, accounting for subgroup } \\
\text { effect and treatment-subgroup } \\
\text { interaction, and three-way interaction, } \\
\text { FDR control to account for multiplicity }\end{array}$ \\
\hline & $\mathrm{ITT}$ & $\begin{array}{l}\text { Baseline pre-dialysis plasma } \mathrm{Na}+\text { ionic } \\
\text { activity subgroups (observed median } \\
\text { plasma Na+ ionic activity as the level } \\
\text { boundary) }\end{array}$ & Primary & $\begin{array}{l}\text { Univariate, accounting for subgroup } \\
\text { effect and treatment-subgroup } \\
\text { interaction }\end{array}$ \\
\hline & $\mathrm{ITT}$ & $\begin{array}{l}\text { Baseline pre-dialysis plasma } \mathrm{Na}+ \\
\text { ilonic activity subgroups (observed } \\
\text { median plasma } \mathrm{Na}+\text { ionic activity as } \\
\text { the level boundary) }\end{array}$ & $\begin{array}{l}\text { Time-averaged blood pressure over } \\
\text { months } 3,6,9 \text { and } 12 \text { (intra-dialytic, inter- } \\
\text { dialytic), \% maximum recommended daily } \\
\text { dose of antihypertensives }\end{array}$ & $\begin{array}{l}\text { Univariate, accounting for subgroup } \\
\text { effect and treatment-subgroup } \\
\text { interaction, and three-way interaction, } \\
\text { FDR control to account for multiplicity }\end{array}$ \\
\hline Tolerability & $\mathrm{ITT}$ & None & Hypotension event counts & $\begin{array}{l}\text { Multivariate, mixed effects, allowing } \\
\text { for treatment time interaction }\end{array}$ \\
\hline
\end{tabular}

Abbreviations: PP per protocol, ITT intention to treat, $L V M I$ left ventricular mass index, FDR False Discovery Rate.

All tests of significance of hypotheses concerning treatment effect parameters will be carried out using a level of significance of $5 \%$ and two-sided alternatives. The significance threshold of potential covariates will be set at $10 \%$, to promote unbiased and conservative inference. All estimates will be produced as point estimates and as $95 \%$ confidence intervals. Unless otherwise noted, model selection when required will be performed using backward selection from the largest model dictated by the situation. Per comparison error rate (PCER) control will be used in all analyses, with the exception of some subgroup analyses where False Discovery Rate (FDR) control will be implemented.

\section{Primary outcome}

For LVMI, we will undertake univariate (single outcome) endpoint analysis. Score residuals will be checked for approximate normality and an appropriate normalising transformation applied to the endpoint data if appropriate and possible. We will use analysis of covariance (ANCOVA) to estimate the treatment effect, adjusting for baseline and potentially adjusting for covariates, if applicable. The resulting treatment contrast will be reported as a point estimate and as a $95 \%$ confidence interval.

\section{Secondary outcomes}

For all secondary outcomes other than health-related quality of life, we will undertake multivariate (repeated outcomes) endpoint analysis. For health-related quality of life, we will use univariate analyses in a manner similar to that presented for the primary outcome. Otherwise, analyses will fit all outcomes as repeated measures over the 2-4 assessment time points to an appropriate regression model using generalised estimating equations (GEEs). Changes from baseline will be associated with the assessment time (from baseline), the treatment arm, and the interaction of the two, adjusting for baseline and potentially for other confounding covariates, if applicable, similarly to the procedure outlined above for the primary outcome. The procedure will account for clustering on subjects; independent, exchangeable and autoregressive working correlation structures will be used and the best option in terms of Quasilikelihood Information Criterion retained for the final analyses [176]. Time-averaged analyses will be implemented by appropriately weighting each observation, accounting for any missing time point, so as to produce inference on the estimated average value over the available individual follow-up period. All results will be estimates 
of treatment effect and treatment-time interaction contrasts. Results will be reported as the point estimates and $95 \%$ confidence intervals for these quantities.

\section{Contingency for non-normality}

Equivalent analyses after a normalising data transformation will be carried out if non-normality of outcomes is evinced. The choice of transformation will be guided by the stabilisation of variance. Notable departures from normality of residuals after regression of the transformed data, as evinced by visual assessments and formal tests of normality of residuals, will result in an alternative approach. When a transformation is applied, location estimates and confidence intervals will be transformed back to the original scale, with first-degree bias correction.

\section{Missing data}

Every effort will be made to minimise missing data. Missing outcome data will cause the patient/time point instance to be removed from the analysis. In the case of time-averaged endpoints, non-missing data will be appropriately reweighted. Joint modelling of missingness and the primary outcome will be carried out, for sensitivity assessment, if missingness exceeds $10 \%$ or is significantly different between the intervention arms at the $5 \%$ level.

\section{Subgroup analyses}

Subgroup analyses will be performed for the primary outcome and time-averaged BP (intra-dialytic, inter-dialytic, percentage maximum recommended daily dose of antihypertensives) according to the baseline severity of LV hypertrophy, baseline severity of hypertension, and baseline predialysis plasma $\gamma \mathrm{Na}$. Subgroup analyses will be carried on using interaction of the groups thus defined and the treatment arms.

\section{Tolerability analysis}

Tolerability of dialysis will be compared between the two arms by assessing the frequency of intra-dialytic hypotension episodes using negative binomial regression of the number of events as dependent variable and the logarithm of the duration of the period covered (normally two weeks, prior to assessment). To identify any effect of prolonged exposure to the treatment, the dependent variable will be similarly modelled as a repeated measure on the time of assessment, the treatment arm and their interaction. To maintain interpretability at the patient level, conditional (mixed effects) rather than marginal (GEE) methodology will be used to estimate tolerability trends. Normally distributed random effects will account for the baseline dialysis tolerance in each participant. The treatment and treatment interaction contrasts from the tolerability analyses will be reported as point estimates and $95 \%$ confidence intervals.

\section{Discussion}

The SoLID trial will be the first randomised controlled trial to investigate the effect lower dialysate $[\mathrm{Na}+]$ upon $\mathrm{LV}$ structure and function. The outcomes of this research will provide compelling evidence about the efficacy of lower dialysate $[\mathrm{Na}+]$ to improve $\mathrm{CV}$ outcomes in hemodialysis populations. As importantly, the SoLID trial will provide novel data with respect to important patient centred outcomes, and evaluate the effect of lower dialysate $[\mathrm{Na}+]$ on thirst, xerostomia, HRQoL and intra-dialytic hypotension. If the benefit of lower dialysate $[\mathrm{Na}+]$ is confirmed, other benefits might also flow on from reduced CV morbidity and mortality, including improvements in general health status, and conceivably fewer hospitalisations and improvements in social/employment rehabilitation. Logistically, lower dialysate $[\mathrm{Na}+]$ is a simple and cost-free intervention, and widespread implementation would be easy for home HD patients and selected facility HD patients.

The comprehensive range of secondary outcomes and the use of gold standard measurements further strengthen the trial. These data allows for their simultaneous evaluation as intermediary variables on the causall pathway to LV hypertrophy. Such data have not been previously reported in the setting of clinical trial, where fundamental changes are made to conditions with simultaneous measurement of downstream physiological parameters. Such data will improve understanding of the patho-biology and causall mechanisms of LV hypertrophy, and in particular the contributions of uncontrolled hypertension and ECF overload. Data from the SoLID trial will allow the development of a hierarchy of importance for the various factors that increase LV mass. There is a strong likelihood of novel relationships and hypotheses emerging, in turn leading to further research in both bench and clinical settings.

In terms of internal validity, the strengths of the SoLID trial are that it is prospective and randomised, with robust allocation concealment and analysis of cardiac MRI data in duplicate by two blinded independent analysts who will remain unaware of the allocation of participants for the duration of the trial. A limitation of the trial pertains to secondary outcomes. All baseline measurements of secondary outcomes will be made prior to randomisation. However, once randomisation has occurred, participants and assessors for the follow-up measurements will not be blinded to treatment. For instance, bioimpedance and pulse wave procedures and measurements will be performed by research associates who will be potentially aware of the allocation of participants. This may bias participants' and research associates' perception of tolerance to the intervention, and their reporting of subjective scoring surveys such as thirst and xerostomia inventories and HRQoL questionnaires. The impact of any actual bias is likely to be mitigated through completion is baseline 
measurements prior to randomisation, but certainly not abrogated.

Of note, the SoLID Trial excludes those who are on dialysis more than 3.5 times per week to avoid confounding the effect of dialysate $[\mathrm{Na}+]$ on LV mass by frequent or nocturnal dialysis. The study will not exclude those whose HD treatments are unconventionally long ( $\sim 8$ hours per treatment) so long as they are undergoing HD no more than 3.5 times per week. This is based on the high reported prevalence of LV hypertrophy in populations treated with this manner (notwithstanding the overestimation of LV mass by echocardiography that biases these studies [175]): $87 \%$ of patients in Christchurch NZ [124], $76 \%$ of those in Manchester UK [177], and in more than 80\% of those in Tassin France [178]. LV hypertrophy is still present in these populations on long-hour dialysis as a result of BP variability, neurohormonal factors and residual positive sodium balance, all of which are potentially modifiable with lower dialysate $[\mathrm{Na}+]$.

In terms of external validity, the major limitation of the SoLID trial is the research setting of home HD. Participants are likely to have less medical co-morbidity than facility HD patients, a factor that was a prime consideration in the development of the sampling frame for the SoLID trial. Such patients are less prone to intradialytic hypotension, which minimizes the chances of participant dropout from intolerance to the lower dialysate $[\mathrm{Na}+]$ in the trial. As a result, the SoLID trial may not be immediately applicable to dialysis patients with a high burden on medical co-morbidity who are more prone to intra-dialytic hypotension. Notwithstanding, the SoLID trial may provide valuable proof-of-concept data for future research in this patient population, depending on the clinical characteristics of patients eventually recruited to the trial.

As with any clinical trial, recruitment will be a key element. Feasibility analysis of the participating 6 centres has indicated a sufficiently large pool of potential participants assuming a $33 \%$ conversion rate. A pilot study previously undertaken by the SoLID research group showed good tolerance to lower dialysate with minimal adverse events, and we do not anticipate excess loss of participants due to intolerance of the trial intervention [89]. The $25 \%$ dropout rate we modelled in power calculations accounts for technique failure in the modern NZ home HD population. A potential risk to recruitment lies with the collection of so many secondary endpoints and their need to occur at specific times on the participants' dialysis schedules, which may make the trial unattractive to some patients. Slow recruitment will be managed by the expansion of the SoLID trial to include a $7^{\text {th }}$ site in NZ or Australia, as required.

In conclusion, the SoLID trial will provide compelling evidence about the use of lower dialysate $[\mathrm{Na}+]$ to improve CV outcomes, and potentially improve understanding of the biological mechanisms underlying the development and persistence of LV hypertrophy. If the benefit of lower dialysate $[\mathrm{Na}+]$ is confirmed, the SoLID Trial will contribute a cost-free economically sustainable improvement to dialysis practice. This, and the immediately availability of the intervention to HD patients, will allow for optimal and maximal translation into clinical effectiveness and benefit.

\section{Abbreviations}

HD: Hemodialysis; ESKD: End-stage kidney disease; ANZDATA: Australian and New Zealand dialysis and transplant registry; SCD: Sudden cardiac death; LV: Left ventricular; LVH: Left ventricular hypertrophy; ECF: Extra-cellular fluid; BP: Blood pressure; IDWG: Intra-dialytic weight gain; LVMI: Left ventricular mass index; CAMRI: Centre for advanced magnetic resonance imaging; DMC: Data monitoring committee; CV: Cardiovascular; CKD: Chronic kidney disease; LDL: Low density lipoprotein; IVRS: Interactive voice response system; NHMRC: National (Australia) health medical research Council; CTC:

MRI: Magnetic resonance imaging; NT-pro-BNP: N Terminal pro Brain Natretic Peptide; BCM: Body composition monitor; hsCRP: high sensitivity C-Reactive Protein; PWV: Pulse wave velocity; PWA: Pulse wave analysis; SD: Standard deviation; PTT: Pulse transit time; YNa: Ionic sodium; NKF-KJDOQI: National kidney foundation kidney disease outcomes quality initiative; HRQoL: Health related quality of life; SOLID: Sodium lowering in dialysis; ANCOVA: Analysis of Co-variance; ITT: Intention to treat; PP: Per protocol; PCER: Per comparison error rate; GEE: Generalised estimating equation; FDR: False discovery rate.

\section{Competing interests}

The authors declare that they have no competing interests.

\section{Authors' contributions}

JLD participated in the trial design, and drafted the manuscript. ACV participated in the trial design, developed the statistical plan, and helped to draft the manuscript. MRM conceived and developed the trial, and participated in the statistical plan and helped to draft the manuscript. RSG, $\mathrm{IAH}$, and DORM participated in design and development of the trial, and helped to draft the manuscript. JRdZ and PJM participated in the trial design and coordination, and helped to draft the manuscript. CJH, KSR, and DJS participated in the trial coordination and implementation, and helped to draft the manuscript. All authors read and approved the final manuscript.

\section{Authors' information}

JLD is a Senior Lecturer at the Auckland Clinical School, Faculty of Medical and Health Sciences, University of Auckland, Private Bag 93311, Otahuhu, Auckland 1640, New Zealand, and a specialist nephrologist within the Department of Renal Medicine, Middlemore Hospital, Counties Manukau District Health Board, Private Bag 93311, Otahuhu, Auckland 1640, New Zealand. ACV is a statistical mathematician within the Faculty of Health and Environmental Sciences, Auckland University of Technology, North Shore Campus, Private Bag 92006, Auckland 1142, New Zealand. JRdZ is a specialist nephrologist within the Renal Service, North Shore Hospital, Waitemata District Health Board, Private Bag 93503, Takapuna, Auckland 0740, New Zealand. RSG is a specialist cardiologist within the Department of Cardiology, Middlemore Hospital, Counties Manukau District Health Board, Private Bag 93311, Otahuhu, Auckland 1640, New Zealand. IAH and DJS are specialist nephrologists within the Department of Renal Medicine, Auckland City Hospital, Auckland District Health Board, Private Bag 92024, Auckland, Auckland 0740 , New Zealand. $\mathrm{CJH}$ is a specialist nephrologist within the Department of Renal Medicine, Middlemore Hospital, Counties Manukau District Health Board, Private Bag 93311, Otahuhu, Auckland 1640, New Zealand. PJM is a specialist nephrologist within the Department of Nephrology, Wellington Hospital, Capital \& Coast District Health Board, Private Bag 7902, Wellington South, New Zealand. DORM is a specialist nephrologist within the Department of Nephrology, Christchurch Hospital, Canterbury District Health Board, Private Bag 4710, Christchurch, New Zealand. KSR is a specialist nephrologist within the Department of Renal Medicine, Waikato Hospital, Waikato District Health Board, Private Bag 3200, Hamilton 3240, New Zealand. MRM is an honorary Associate Professor at the 
Auckland Clinical School, Faculty of Medical and Health Sciences, University of Auckland, Private Bag 93311, Otahuhu, Auckland 1640, New Zealand, and the Clinical Director of the Department of Renal Medicine, Middlemore Hospital, Counties Manukau District Health Board, Private Bag 93311, Otahuhu, Auckland 1640, New Zealand.

\section{Acknowledgements}

The SoLID trial is funded through grants from the Health Research Council of New Zealand, the Maurice and Phyllis Paykel Trust and the Royal Australasian College of Physicians (RACP) Research Foundation. JLD is a current recipient of an RACP Jacquot Research Entry Scholarship, and MRM is a current recipient of an RACP Jacquot Research Establishment Fellowships. The SoLID trial research team would like to acknowledge the kindness of the Jacquot Family in supporting nephrological research in Australasia, and the kindness of Mr and Mrs Kwun Kwok and their son Mr Siu Hang Kok for supporting nephrological research at Counties Manukau District Health Board. The SoLID trial research team would also like to acknowledge the Australasian Kidney Trial Network (www.aktn.org.au), for providing advice and assistance on the design of the trial.

\begin{abstract}
Author details
${ }^{1}$ South Auckland Clinical School, Faculty of Medical and Health Sciences, University of Auckland, Private Bag 93311. Otahuhu, Auckland 1640, New Zealand. ${ }^{2}$ Department of Renal Medicine, Middlemore Hospital, Counties Manukau District Health Board, Private Bag 93311, Otahuhu, Auckland 1640, New Zealand. ${ }^{3}$ Faculty of Health and Environmental Sciences, Auckland University of Technology, North Shore Campus, Private Bag 92006, Auckland 1142, New Zealand. ${ }^{4}$ Renal Service, North Shore Hospital, Waitemata District Health Board, Private Bag 93503, Takapuna, Auckland 0740, New Zealand. ${ }^{5}$ Department of Cardiology, Middlemore Hospital, Counties Manukau District Health Board, Private Bag 93311, Otahuhu, Auckland 1640, New Zealand. ${ }^{6}$ Department of Renal Medicine, Auckland City Hospital, Auckland District Health Board, Private Bag 92024, Auckland 0740, New Zealand. 'Department of Nephrology, Wellington Hospital, Capital \& Coast District Health Board, Private Bag 7902, Wellington South, New Zealand. ${ }^{8}$ Department of Nephrology, Christchurch Hospital, Canterbury District Health Board, Private Bag 4710, Christchurch, New Zealand. ${ }^{9}$ Department of Renal Medicine, Waikato Hospital, Waikato District Health Board, Private Bag 3200, Hamilton 3240, New Zealand.
\end{abstract}

Received: 22 April 2013 Accepted: 8 July 2013 Published: 15 July 2013

\section{References}

1. U.S. Renal Data System, USRDS 2012 Annual Data Report: Atlas of End-stage renal disease in the united states, national institutes of health, national institute of diabetes and digestive and kidney diseases. Bethesda, MD; 2012.

2. McDonald S: ANZDATA Registry Report, Australia and New Zealand Dialysis and Transplant Registry, Adelaide, South Australia. 2011.

3. Marshall MR, Hawley CM, Kerr PG, Polkinghorne KR, Marshall RJ, Agar JW, McDonald SP: Home hemodialysis and mortality risk in Australian and New Zealand populations. Am J Kidney Dis 2011, 58(5):782-793.

4. Zipes DP, Wellens HJ: Sudden cardiac death. Circulation 1998, 98(21):2334-2351.

5. Herzog CA, Mangrum JM, Passman R: Sudden cardiac death and dialysis patients. Semin Dial 2008, 21(4):300-307.

6. Herzog CA, Strief JW, Collins AJ, Gilbertson DT: Cause-specific mortality of dialysis patients after coronary revascularization: why don't dialysis patients have better survival after coronary intervention? Nephrol Dial Transplant 2008, 23(8):2629-2633.

7. Nishimura M, Tokoro T, Nishida M, Hashimoto T, Kobayashi H, Yamazaki S, Imai R, Okino K, Iwamoto N, Takahashi H, et al: Sympathetic overactivity and sudden cardiac death among hemodialysis patients with left ventricular hypertrophy. Int J Cardiol 2010, 142(1):80-86.

8. Zoccali C, Benedetto FA, Tripepi G, Mallamaci F: Cardiac consequences of hypertension in hemodialysis patients. Semin Dial 2004, 17(4):299-303.

9. Ritz $\mathrm{E}$, Wanner $\mathrm{C}$ : The challenge of sudden death in dialysis patients. Clin J Am Soc Nephrol 2008, 3(3):920-929.

10. Amann K, Kronenberg G, Gehlen F, Wessels S, Orth S, Munter K, Ehmke $H$, Mall G, Ritz E: Cardiac remodelling in experimental renal failure-an immunohistochemical study. Nephrol Dial Transplant 1998, 13(8):1958-1966.

11. Amann K, Breitbach M, Ritz E, Mall G: Myocyte/capillary mismatch in the heart of uremic patients. J Am Soc Nephrol 1998, 9(6):1018-1022.

12. Glassock RJ, Pecoits-Filho R, Barberato SH: Left ventricular mass in chronic kidney disease and ESRD. Clin J Am Soc Nephrol 2009, 4(Suppl 1):S79-S91.

13. Diwan A, Wansapura J, Syed FM, Matkovich SJ, Lorenz JN, Dorn GW 2nd: Nix-mediated apoptosis links myocardial fibrosis, cardiac remodeling, and hypertrophy decompensation. Circulation 2008, 117(3):396-404.

14. Dorn GW 2nd: Apoptotic and non-apoptotic programmed cardiomyocyte death in ventricular remodelling. Cardiovasc Res 2009, 81(3):465-473.

15. Gross ML, Ritz E: Hypertrophy and fibrosis in the cardiomyopathy of uremia-beyond coronary heart disease. Semin Dial 2008, 21(4):308-318.

16. Nishida K, Kyoi S, Yamaguchi O, Sadoshima J, Otsu K: The role of autophagy in the heart. Cell Death Differ 2009, 16(1):31-38.

17. Silberberg JS, Barre PE, Prichard SS, Sniderman AD: Impact of left ventricular hypertrophy on survival in end-stage renal disease. Kidney Int 1989, 36(2):286-290.

18. Baigent C, Landray MJ, Reith C, Emberson J, Wheeler DC, Tomson C, Wanner C, Krane V, Cass A, Craig J, et al: The effects of lowering LDL cholesterol with simvastatin plus ezetimibe in patients with chronic kidney disease (Study of Heart and Renal Protection): a randomised placebo-controlled trial. Lancet 2011, 377(9784):2181-2192.

19. Fellstrom BC, Jardine AG, Schmieder RE, Holdaas H, Bannister K, Beutler J, Chae DW, Chevaile A, Cobbe SM, Gronhagen-Riska C, et al: Rosuvastatin and cardiovascular events in patients undergoing hemodialysis. N Engl J Med 2009, 360(14):1395-1407

20. Wanner C, Krane V, Marz W, Olschewski M, Mann JF, Ruf G, Ritz E, German Diabetes and Dialysis Study I: Atorvastatin in patients with type 2 diabetes mellitus undergoing hemodialysis. N Engl J Med 2005, 353(3):238-248.

21. Palmer SC, Craig JC, Navaneethan SD, Tonelli M, Pellegrini F, Strippoli GF: Benefits and harms of statin therapy for persons with chronic kidney disease: a systematic review and meta-analysis. Ann Intern Med 2012, 157(4):263-275.

22. Parker T 3rd, Hakim R, Nissenson AR, Steinman T, Glassock RJ: Dialysis at a crossroads: 50 years later. Clin J Am Soc Nephrol 2011, 6(2):457-461.

23. Parker TF 3rd, Glassock RJ, Steinman TI: Conclusions, consensus, and directions for the future. Clin J Am Soc Nephrol 2009, 4(Suppl 1):S139-S144.

24. Charra B, Calemard E, Ruffet M, Chazot C, Terrat J, Vanel T, Laurent G: Survival as an index of adequacy of dialysis. Kidney Int 1992, 41:1286-1291.

25. Charra B, Chazot C, Jean G, Hurot JM, Terrat JC, Vanel T, Lorriaux C, Vovan C: Role of sodium in dialysis. Minerva Urol Nefrol 2004, 56(3):205-213.

26. London GM, Pannier B, Guerin AP, Blacher J, Marchais SJ, Darne B, Metivie $F$, Adda H, Safar ME: Alterations of left ventricular hypertrophy in and survival of patients receiving hemodialysis: follow-up of an interventional study. J Am Soc Nephrol 2001, 12(12):2759-2767.

27. Ozkahya M, Ok E, Cirit M, Aydin S, Akcicek F, Basci A, Dorhout Mees EJ: Regression of left ventricular hypertrophy in haemodialysis patients by ultrafiltration and reduced salt intake without antihypertensive drugs. Nephrol Dial Transplant 1998, 13(6):1489-1493.

28. Ozkahya M, Toz H, Qzerkan F, Duman S, Ok E, Basci A, Mees E: Impact of volume control on left ventricular hypertrophy in dialysis patients. J Nephrol 2002, 15:655-660

29. Koc Y, Unsal A, Kayabasi H, Oztekin E, Sakaci T, Ahbap E, Yilmaz M, Akgun AO: Impact of volume status on blood pressure and left ventricle structure in patients undergoing chronic hemodialysis. Ren Fail 2011, 33(4):377-381

30. Li H, Wang SX: Improvement of hypertension and LVH in maintenance hemodialysis patients treated with sustained-release isosorbide mononitrate. J Nephrol 2011, 24(2):236-245.

31. Mominadam S, Ozkahya M, Kayikcioglu M, Toz H, Asci G, Duman S, Ergin P Kirbiyik S, Ok E, Basci A: Interdialytic blood pressure obtained by ambulatory blood pressure measurement and left ventricular structure in hypertensive hemodialysis patients. Hemodial Int 2008, 12(3):322-327.

32. Inal S, Erten Y, Akbulu G, Onec K, Tek NA, Sahin G, Okyay GU, Sanlier N: Salt intake and hypervolemia in the development of hypertension in peritoneal dialysis patients. Adv Perit Dial 2012, 28:10-15. 
33. Patel RK, Oliver S, Mark PB, Powell JR, McQuarrie EP, Traynor JP, Dargie HJ, Jardine AG: Determinants of left ventricular mass and hypertrophy in hemodialysis patients assessed by cardiac magnetic resonance imaging. Clin J Am Soc Nephrol 2009, 4(9):1477-1483.

34. Chertow GM, Levin NW, Beck GJ, Depner TA, Eggers PW, Gassman JJ, Gorodetskaya I, Greene T, James S, Larive B, et al: In-center hemodialysis six times per week versus three times per week. N Engl J Med 2010, 363(24):2287-2300.

35. Culleton BF, Walsh M, Klarenbach SW, Mortis G, Scott-Douglas N, Quinn RR, Tonelli M, Donnelly S, Friedrich MG, Kumar A, et al: Effect of frequent nocturnal hemodialysis vs conventional hemodialysis on left ventricular mass and quality of life: a randomized controlled trial. JAMA 2007, 298(11):1291-1299.

36. Foley RN, Parfrey PS, Kent GM, Harnett JD, Murray DC, Barre PE: Serial change in echocardiographic parameters and cardiac failure in endstage renal disease. J Am Soc Nephrol 2000, 11(5):912-916.

37. Zoccali C, Benedetto FA, Mallamaci F, Tripepi G, Giacone G, Stancanelli B, Cataliotti A, Malatino LS: Left ventricular mass monitoring in the follow-up of dialysis patients: prognostic value of left ventricular hypertrophy progression. Kidney Int 2004, 65(4):1492-1498.

38. Wilson J, Shah T, Nissenson AR: Role of sodium and volume in the pathogenesis of hypertension in hemodialysis. Semin Dial 2004, 17(4):260-264

39. Wald R, Yan AT, Perl J, Jiang D, Donnelly MS, Leong-Poi H, McFarlane PA, Weinstein JJ, Goldstein MB: Regression of left ventricular mass following conversion from conventional hemodialysis to thrice weekly in-centre nocturnal hemodialysis. BMC Nephrol 2012, 13:3.

40. Chan CT, Floras JS, Miller JA, Richardson RM, Pierratos A: Regression of left ventricular hypertrophy after conversion to nocturnal hemodialysis. Kidney Int 2002, 61(6):2235-2239.

41. Marshall MR, Dunlop JL: Are dialysate sodium levels too high? Semin Dial 2012, 25(3):277-283

42. Blankestijn PJ, Ligtenberg G: Volume-independent mechanisms of hypertension in hemodialysis patients: clinical implications. Semin Dial 2004, 17(4):265-269.

43. Friedman SM, Mclndoe RA, Tanaka M: The relation of blood sodium concentration to blood pressure in the rat. J Hypertens 1990, 8(1):61-66.

44. He FJ, Fan S, Macgregor GA, Yaqoob MM: Plasma sodium and blood pressure in individuals on haemodialysis. J Hum Hypertens 2013, 27(2):85-89.

45. Tobian L, Hanlon S: High sodium chloride diets injure arteries and raise mortality without changing blood pressure. Hypertension 1990, 15(6 Pt 2):900-903.

46. Oberleithner $\mathrm{H}$, Riethmuller C, Schillers H, MacGregor GA, de Wardener HE, Hausberg M: Plasma sodium stiffens vascular endothelium and reduces nitric oxide release. Proc Natl Acad Sci USA 2007, 104(41):16281-16286.

47. Levin A, Goldstein MB: The benefits and side effects of ramped hypertonic sodium dialysis. J Am Soc Nephrol 1996, 7(2):242-246.

48. Sang GL, Kovithavongs C, Ulan R, Kjellstrand CM: Sodium ramping in hemodialysis: a study of beneficial and adverse effects. Am J Kidney Dis 1997, 29(5):669-677.

49. Munoz Mendoza J, Sun S, Chertow GM, Moran J, Doss S, Schiller B: Dialysate sodium and sodium gradient in maintenance hemodialysis: a neglected sodium restriction approach? Nephrol Dial Transplant 2011, 26(4):1281-1287.

50. Martinez-Vea A, Garcia C, Gaya J, Rivera F, Oliver JA: Abnormalities of thirst regulation in patients with chronic renal failure on hemodialysis. Am J Nephrol 1992, 12(1-2):73-79.

51. Gumrukcuoglu HA, Ari E, Akyol A, Akdag S, Simsek H, Sahin M, Gunes Y, Tuncer M: Effects of lowering dialysate sodium on carotid artery atherosclerosis and endothelial dysfunction in maintenance hemodialysis patients. Int Urol Nephrol 2012, 44(6):1833-1839.

52. Daugirdas JT, Al-Kudsi RR, Ing TS, Norusis MJ: A double-blind evaluation of sodium gradient hemodialysis. Am J Nephrol 1985, 5(3):163-168.

53. Dominic SC, Ramachandran S, Somiah S, Mani K, Dominic SS: Quenching the thirst in dialysis patients. Nephron 1996, 73(4):597-600.

54. Wilkinson R, Barber SG, Robson V: Cramps, thirst and hypertension in hemodialysis patients - the influence of dialyzate sodium concentration. Clin Nephrol 1977, 7(3):101-105.

55. Zwiech R, Bruzda-Zwiech A: The dual blockade of the renin-angiotensin system in hemodialysis patients requires decreased dialysate sodium concentration. Int Urol Nephrol 2012.
56. Lambie SH, Taal MW, Fluck RJ, Mclntyre CW: Online conductivity monitoring: validation and usefulness in a clinical trial of reduced dialysate conductivity. ASAIO J 2005, 51(1):70-76.

57. Davenport A: Audit of the effect of dialysate sodium concentration on inter-dialytic weight gains and blood pressure control in chronic haemodialysis patients. Nephron Clin Pract 2006, 104(3):C120-c125.

58. Fischbach $M$, Tarral E, Geisert J: Sequential hypertonic haemodialysis in children. Pediatr Nephrol 1988, 2(4):442-446.

59. Henrich WL, Woodard TD, MCPhaul JJ Jr: The chronic efficacy and safety of high sodium dialysate: double-blind, crossover study. Am J Kidney Dis 1982, 2(3):349-353.

60. Boquin E, Parnell S, Grondin G, Wollard C, Leonard D, Michaels R, Levin NW: Crossover study of the effects of different dialysate sodium concentrations in large surface area, short-term dialysis. Proc Clin Dial Transplant Forum 1977, 7:48-52.

61. Tang HL, Wong SH, Chu KH, Lee W, Cheuk A, Tang CM, Kong IL, Fung KS, Tsang WK, Chan HW, et al: Sodium ramping reduces hypotension and symptoms during haemodialysis. Hong Kong Med J 2006, 12(1):10-14

62. Song JH, Lee SW, Suh CK, Kim MJ: Time-averaged concentration of dialysate sodium relates with sodium load and interdialytic weight gain during sodium-profiling hemodialysis. Am J Kidney Dis 2002, 40(2):291-301.

63. Shah A, Davenport A: Does a reduction in dialysate sodium improve blood pressure control in haemodialysis patients? Nephrology (Carlton) 2012, 17(4):358-363.

64. Sandhu E, Crawford C, Davenport A: Weight gains and increased blood pressure in outpatient hemodialysis patients due to change in acid dialysate concentrate supplier. Int J Artif Organs 2012, 35(9):642-647.

65. Munoz Mendoza J, Bayes LY, Sun S, Doss S, Schiller B: Effect of lowering dialysate sodium concentration on interdialytic weight gain and blood pressure in patients undergoing thrice-weekly in-center nocturnal hemodialysis: a quality improvement study. Am J Kidney Dis 2011, 58(6):956-963

66. Manlucu J, Gallo K, Heidenheim PA, Lindsay RM: Lowering postdialysis plasma sodium (conductivity) to increase sodium removal in volumeexpanded hemodialysis patients: a pilot study using a biofeedback software system. Am J Kidney Dis 2010, 56(1):69-76.

67. Levin NW, Zhu F, Keen M: Interdialytic weight gain and dry weight. Blood Purif 2001, 19(2):217-221.

68. Ireland R: Dialysis: Does reducing dialysate sodium level lower blood pressure? Nat Rev Nephrol 2012, 8(4):192.

69. Del Giudice A, Cicchella A, Di Giorgio G, Piemontese M, Prencipe M Fontana A, Copetti M, Pellegrini F, Aucella F: [Prevalence and control of hypertension in chronic hemodialysis patients: results of a single-centre clinical audit]. G Ital Nefrol 2012, 29(2):230-237.

70. Barre $P E$, Brunelle $G$, Gascon-Barre $M$ : A randomized double blind trial of dialysate sodiums of $145 \mathrm{mEq} / \mathrm{L}, 150 \mathrm{mEq} / \mathrm{L}$, and $155 \mathrm{mEq} / \mathrm{L}$. ASAIO Trans 1988, 34(3):338-341.

71. Arramreddy R, Sun SJ, Munoz Mendoza J, Chertow GM, Schiller B: Individualized reduction in dialysate sodium in conventional in-center hemodialysis. Hemodial Int 2012, 16(4):473-480.

72. Hecking M, Karaboyas A, Saran R, Sen A, Inaba M, Rayner H, Horl WH, Pisoni $\mathrm{RL}$, Robinson BM, Sunder-Plassmann $\mathrm{G}$, et al: Dialysate sodium concentration and the association with interdialytic weight gain, hospitalization, and mortality. Clin J Am Soc Nephrol 2012, 7(1):92-100.

73. Hecking M, Kainz A, Horl WH, Herkner H, Sunder-Plassmann G: Sodium setpoint and sodium gradient: influence on plasma sodium change and weight gain. Am J Nephrol 2011, 33(1):39-48.

74. Hamzi AM, Asseraji M, Hassani K, Alayoud A, Abdellali B, Zajjari Y, Montacer DB, Akhmouch I, Benyahia M, Oualim Z: Applying sodium profile with or without ultrafiltration profile failed to show beneficial effects on the incidence of intradialytic hypotension in susceptible hemodilaysis patients. Arab J Nephrol Transplant 2012, 5(3):129-134.

75. Davenport A, Cox C, Thuraisingham R: The importance of dialysate sodium concentration in determining interdialytic weight gains in chronic hemodialysis patients: the PanThames Renal Audit. Int J Artif Organs 2008, 31(5):411-417.

76. Ebel H, Laage C, Keuchel M, Dittmar A, Saure B, Ehlenz K, Lange H: Impact of profile haemodialysis on intra-/extracellular fluid shifts and the release of vasoactive hormones in elderly patients on regular dialysis treatment. Nephron 1997, 75(3):264-271. 
77. Ogden DA: A double blind crossover comparison of high and low sodium dialysis. Proc Clin Dial Transplant Forum 1978, 8:157-165.

78. Oliver MJ, Edwards $\sqcup$, Churchill DN: Impact of sodium and ultrafiltration profiling on hemodialysis-related symptoms. J Am Soc Nephrol 2001, 12 (1):151-156

79. Kimura G, Gotch FA: Serum sodium concentration and body fluid distribution during interdialysis: importance of sodium to fluid intake ratio in hemodialysis patients. Int J Artif Organs 1984, 7(6):331-336.

80. Van Stone JC, Bauer J, Carey J: The effect of dialysate sodium concentration on body fluid compartment volume, plasma renin activity and plasma aldosterone concentration in chronic hemodialysis patients. Am J Kidney Dis 1982, 2(1):58-64.

81. Krautzig S, Janssen U, Koch K, Granolleras C, Shaldon S: Dietary salt restriction and reduction of dialysate sodium to control hypertension in maintenance haemodialysis patients. Nephrol Dial Transplant 1998, 13:552-553.

82. Krautzig S, Kielstein J, Granolleras C, Shaldon S, Lonnemann G, Koch K: Control of hypertension in HD pateints by reduction of dialysate sodium and low salt diet. J Am Soc Nephrol 1997, 8:243A. Abstr.

83. Farmer CKT, Donohoe P, Dallyn P, Cox J, Kingswood JC, Goldsmith DJA: Low-sodium haemodialysis without fluid removal improves blood pressure control in chronic haemodialysis patients. Nephrology (Carlton) 2000, 5(4):237-241.

84. Parsons D, Yuill E, Llapitan M, Harris D: Sodium modelling and profiled ultrafiltration in conventional haemodialysis. Nephrology (Carlton) 1997 3:177-182.

85. Dumler F, Grondin G, Levin NW: Sequential high/low sodium hemodialysis: an alternative to ultrafiltration. ASAIO Trans 1979, 25:351353.

86. Jenson BM, Dobbe SA, Squillace DP, McCarthy JT: Clinical benefits of high and variable sodium concentration dialysate in hemodialysis patients. ANNA J 1994, 21(2):115-120. discussion 121.

87. Sadowski RH, Allred EN, Jabs K: Sodium modeling ameliorates intradialytic and interdialytic symptoms in young hemodialysis patients. J Am SoC Nephrol 1993, 4(5):1192-1198.

88. Kooman JP, Hendriks EJ, van Den Sande FM, Leumissen KM: Dialysate sodium concentration and blood pressure control in haemodialysis patients. Nephrol Dial Transplant 2000, 15(4):554.

89. Thein H, Haloob I, Marshall MR: Associations of a facility level decrease in dialysate sodium concentration with blood pressure and interdialytic weight gain. Nephrol Dial Transplant 2007, 22(9):2630-2639.

90. Sayarlioglu H, Erkoc R, Tuncer M, Soyoral Y, Esen R, Gumrukcuoglu HA, Dogan E, Sayarlioglu M: Effects of low sodium dialysate in chronic hemodialysis patients: an echocardiographic study. Ren Fail 2007, 29 (2):143-146

91. Aybal Kutlugun A, Erdem Y, Okutucu S, Yorgun H, Atalar E, Arici M: Effects of lowering dialysate sodium on flow-mediated dilatation in patients with chronic kidney disease. Nephrol Dial Transplant 2011, 26(11):36783682 .

92. Hecking M, Karaboyas A, Saran R, Sen A, Horl WH, Pisoni RL, Robinson BM, Sunder-Plassmann G, Port FK: Predialysis serum sodium level, dialysate sodium, and mortality in maintenance hemodialysis patients: the Dialysis Outcomes and Practice Patterns Study (DOPPS). Am J Kidney Dis 2012, 59 (2):238-248

93. Mc Causland FR, Brunelli SM, Waikar SS: Dialysate sodium, serum sodium and mortality in maintenance hemodialysis. Nephrol Dial Transplant 2012 27(4):1613-1618

94. Breidthardt T, McIntyre CW: Dialysis-induced myocardial stunning: the other side of the cardiorenal syndrome. Rev Cardiovasc Med 2011, 12 (1):13-20.

95. Burton JO, Jefferies HJ, Selby NM, McIntyre CW: Hemodialysis-induced cardiac injury: determinants and associated outcomes. Clin J Am Soc Nephrol 2009, 4(5):914-920

96. Burton JO, Jefferies HJ, Selby NM, Mclntyre CW: Hemodialysis-induced repetitive myocardial injury results in global and segmental reduction in systolic cardiac function. Clin J Am Soc Nephrol 2009, 4(12):1925-1931.

97. Burton JO, Korsheed S, Grundy BJ, Mclntyre CW: Hemodialysis-induced left ventricular dysfunction is associated with an increase in ventricular arrhythmias. Ren Fail 2008, 30(7):701-709.

98. Mclntyre CW: Recurrent circulatory stress: the dark side of dialysis. Semin Dial 2010, 23(5):449-451.
99. Curatola G, Bolignano D, Rastelli S, Caridi G, Tripepi R, Tripepi G, Politi R, Catalano F, Delfino D, Ciccarelli $M$, et al: Ultrafiltration intensification in hemodialysis patients improves hypertension but increases AV fistula complications and cardiovascular events. J Nephrol 2011, 24(4):465-473.

100. de Paula FM, Peixoto AJ, Pinto LV, Dorigo D, Patricio PJ, Santos SF: Clinical consequences of an individualized dialysate sodium prescription in hemodialysis patients. Kidney Int 2004, 66(3):1232-1238.

101. Flanigan MJ: Role of sodium in hemodialysis. Kidney Int Supp/ 2000, 76: S72-S78.

102. Gotch FA, Lam MA, Prowitt M, Keen M: Preliminary clinical results with sodium-volume modeling of hemodialysis therapy. Proc Clin Dial Transplant Forum 1980, 10:12-17.

103. Lopot F, Blaha J, Valek A: An equation for calculating postdialysis plasma sodium. Int J Artif Organs 1992, 15(6):354-357.

104. Zerbe RL, Miller JZ, Robertson GL: The reproducibility and heritability of individual differences in osmoregulatory function in normal human subjects. J Lab Clin Med 1991, 117(1):51-59.

105. Raimann JG, Thijssen S, Usvyat LA, Levin NW, Kotanko P: Sodium alignment in clinical practice-implementation and implications. Semin Dial 2011, 24 (5):587-592.

106. Acchiardo SR, Hayden AJ: Is Na + modeling necessary in high flux dialysis? ASAlO Trans 1991, 37(3):M135-M137.

107. Bonomini V, Coli L, Scolari MP: Profiling dialysis: a new approach to dialysis intolerance. Nephron 1997, 75(1):1-6.

108. Titze J: Water-free $\mathrm{Na}+$ retention: interaction with hypertension and tissue hydration. Blood Purif 2008, 26(1):95-99.

109. Titze J: Water-free sodium accumulation. Semin Dial 2009, 22(3):253-255.

110. Titze J, Maillet A, Lang R, Gunga HC, Johannes B, Gauquelin-Koch G, Kihm E, Larina I, Gharib C, Kirsch KA: Long-term sodium balance in humans in a terrestrial space station simulation study. Am J Kidney Dis 2002, 40(3):508516

111. Titze J, Ritz E: Salt and its effect on blood pressure and target organ damage: new pieces in an old puzzle. J Nephrol 2009, 22(2):177-189.

112. Nigwekar S, Wenger J, Thadhani R, Bhan I: Low serum sodium, bone mineral disease and mortality in incident chronic hemodialysis patients. J Am Soc Nephrol 2011, 22:58A.

113. Waikar SS, Curhan GC, Brunelli SM: Mortality associated with low serum sodium concentration in maintenance hemodialysis. Am J Med 2011, 124 (1):77-84.

114. Kovesdy CP, Lott EH, Lu UL, Malakauskas SM, Ma JZ, Molnar MZ, KalantarZadeh K: Hyponatremia, hypernatremia, and mortality in patients with chronic kidney disease with and without congestive heart failure. Circulation 2012, 125(5):677-684.

115. Alderman $\mathrm{MH}$ : The Cochrane review of sodium and health. Am J Hypertens 2011, 24(8):854-856.

116. Taylor RS, Ashton KE, Moxham T, Hooper L, Ebrahim S: Reduced dietary salt for the prevention of cardiovascular disease. Cochrane Database Syst Rev 2011, 7, CD009217

117. Taylor RS, Ashton KE, Moxham T, Hooper L, Ebrahim S: Reduced dietary salt for the prevention of cardiovascular disease: a meta-analysis of randomized controlled trials (Cochrane review). Am J Hypertens 2011, 24 (8):843-853.

118. Garg R, Williams GH, Hurwitz S, Brown NJ, Hopkins PN, Adler GK: Low-salt diet increases insulin resistance in healthy subjects. Metabolism 2011, 60 (7):965-968.

119. Grassi G, Dell'Oro R, Seravalle G, Foglia G, Trevano FQ, Mancia G: Short- and long-term neuroadrenergic effects of moderate dietary sodium restriction in essential hypertension. Circulation 2002, 106(15):1957-1961.

120. Graudal NA, Galloe AM, Garred P: Effects of sodium restriction on blood pressure, renin, aldosterone, catecholamines, cholesterols, and triglyceride: a meta-analysis. JAMA 1998, 279(17):1383-1391.

121. Petrie JR, Morris AD, Minamisawa K, Hilditch TE, Elliott HL, Small M, McConnell J: Dietary sodium restriction impairs insulin sensitivity in noninsulin-dependent diabetes mellitus. J Clin Endocrinol Metab 1998, 83 (5):1552-1557.

122. Covic A, Mardare NG, Ardeleanu S, Prisada O, Gusbeth-Tatomir P, Goldsmith $D J$ : Serial echocardiographic changes in patients on hemodialysis: an evaluation of guideline implementation. J Nephrol 2006, 19(6):783-793.

123. Westlie L, Umen A, Nestrud S, Kjellstrand CM: Mortality, morbidity, and life satisfaction in the very old dialysis patient. Trans Am Soc Artif Intern Organs 1984, 30:21-30. 
124. McGregor DO, Buttimore AL, Nicholls MG, Lynn KL: Ambulatory blood pressure monitoring in patients receiving long, slow home haemodialysis. Nephrol Dial Transplant 1999, 14(11):2676-2679.

125. Petitclerc T, Jacobs C: Dialysis sodium concentration: what is optimal and can it be individualized? Nephrol Dial Transplant 1995, 10(5):596-599.

126. Di Filippo S, Corti M, Andrulli S, Manzoni C, Locatelli F: Determining the adequacy of sodium balance in hemodialysis using a kinetic model. Blood Purif 1996, 14(6):431-436.

127. Di Filippo S, Corti M, Andrulli S, Pontoriero G, Manzoni C, Locatelli F: Optimization of sodium removal in paired filtration dialysis by single pool sodium and conductivity kinetic models. Blood Purif 1997, 15(1):34-44.

128. Murisasco A, France G, Leblond G, Durand C, el Mehdi M, Crevat A, Elsen R, Boobes Y, Baz M: Sequential sodium therapy allows correction of sodiumvolume balance and reduces morbidity. Clin Nephrol 1985, 24(4):201-208.

129. Murisasco A, Leblond G, Elsen R, Stroumza P, Durand C, Jeanningros E, Crevat A, Reynier JP: Equilibration of body water distribution and $\mathrm{Na}+$ balance during hemodialysis (HD) with an ion specific electrode feedback system and integrated computer. Trans Am Soc Artif Intern Organs 1984, 30:254-259.

130. Locatelli F, Di Filippo S, Manzoni C, Corti M, Andrulli S, Pontoriero G: Monitoring sodium removal and delivered dialysis by conductivity. Int $J$ Artif Organs 1995, 18(11):716-721.

131. Bosetto A, Bene B, Petitclerc T: Sodium management in dialysis by conductivity. Adv Ren Replace Ther 1999, 6(3):243-254.

132. Ash S, Campbell K, MacLaughlin H, McCoy E, Chan M, Anderson K, Corke K, Dumont R, Lloyd L, Meade A, et al: Evidence based practice guidelines for the nutritional management of chronic kidney disease. Nutr Diet 2006, 63:S33-S45.

133. Young AA, Cowan BR, Thrupp SF, Hedley WJ, Dell'Italia LJ: Left ventricular mass and volume: fast calculation with guide-point modeling on MR images. Radiology 2000, 216(2):597-602

134. Wang AY, Wai-Kei Lam C: The diagnostic utility of cardiac biomarkers in dialysis patients. Semin Dial 2012, 25(4):388-396

135. Dhar S, Pressman GS, Subramanian S, Kaul S, Gollamudi S, Bloom EJ, Figueredo VM: Natriuretic peptides and heart failure in the patient with chronic kidney disease: a review of current evidence. Postgrad Med J 2009, 85(1004):299-302.

136. Choi SY, Lee JE, Jang EH, Kim MO, Baek H, Ki CS, Park SW, Kim DJ, Huh WS, Oh HY, et al: Association between changes in N-terminal pro-brain natriuretic peptide levels and changes in left ventricular mass index in stable hemodialysis patients. Nephron Clin Pract 2008, 110(2):C93-c100.

137. Roberts MA, Srivastava PM, Macmillan N, Hare DL, Ratnaike S, Sikaris K, lerino FL: B-type natriuretic peptides strongly predict mortality in patients who are treated with long-term dialysis. Clin J Am SoC Nephrol 2008, 3(4):1057-1065.

138. Wang AY, Lam CW, Yu CM, Wang M, Chan IH, Zhang Y, Lui SF, Sanderson JE: N-terminal pro-brain natriuretic peptide: an independent risk predictor of cardiovascular congestion, mortality, and adverse cardiovascular outcomes in chronic peritoneal dialysis patients. J Am Soc Nephrol 2007, 18(1):321-330.

139. Lee JA, Kim DH, Yoo SJ, Oh DJ, Yu SH, Kang ET: Association between serum n-terminal pro-brain natriuretic peptide concentration and left ventricular dysfunction and extracellular water in continuous ambulatory peritoneal dialysis patients. Perit Dial Int 2006, 26(3):360-365.

140. Racek J, Kralova H, Trefil L, Rajdl D, Eiselt J: Brain natriuretic peptide and Nterminal proBNP in chronic haemodialysis patients. Nephron Clin Pract 2006, 103(4):C162-C172.

141. Zoccali C, Mallamaci F: Urotensin II: a cardiovascular and renal update. Curr Opin Nephrol Hypertens 2008, 17(2):199-204.

142. Zoccali C, Mallamaci F, Benedetto FA, Tripepi G, Pizzini P, Cutrupi S, Malatino L: Urotensin II and cardiomyopathy in end-stage renal disease. Hypertension 2008, 51(2):326-333.

143. Ravani P, Tripepi G, Pecchini P, Mallamaci F, Malberti F, Zoccali C: Urotensin II is an inverse predictor of death and fatal cardiovascular events in chronic kidney disease. Kidney Int 2008, 73(1):95-101.

144. Mallamaci F, Cutrupi S, Pizzini P, Tripepi G, Zoccali C: Urotensin II and biomarkers of endothelial activation and atherosclerosis in end-stage renal disease. Am J Hypertens 2006, 19(5):505-510.

145. Zoccali C, Mallamaci F, Tripepi G, Cutrupi S, Pizzini P, Malatino L: Urotensin II is an inverse predictor of incident cardiovascular events in end-stage renal disease. Kidney Int 2006, 69(7):1253-1258.
146. Chen YH, Yandle TG, Richards AM, Palmer SC: Urotensin I immunoreactivity in the human circulation: evidence for widespread tissue release. Clin Chem 2009, 55(11):2040-2048.

147. Dou Y, Zhu F, Kotanko P: Assessment of extracellular fluid volume and fluid status in hemodialysis patients: current status and technical advances. Semin Dial 2012, 25(4):377-387.

148. Davenport A: Negative dialysate to sodium gradient does not lead to intracellular volume expansion post hemodialysis. Int J Artif Organs 2010 33(10):700-705.

149. Kotanko P, Levin NW, Zhu F: Current state of bioimpedance technologies in dialysis. Nephrol Dial Transplant 2008, 23(3):808-812.

150. Agarwal R: The controversies of diagnosing and treating hypertension among hemodialysis patients. Semin Dial 2012, 25(4):370-376.

151. Agarwal R, Metiku T, Tegegne GG, Light RP, Bunaye Z, Bekele DM, Kelley K: Diagnosing hypertension by intradialytic blood pressure recordings. Clin J Am Soc Nephrol 2008, 3(5):1364-1372.

152. Thompson AM, Pickering TG: The role of ambulatory blood pressure monitoring in chronic and end-stage renal disease. Kidney Int 2006, 70(6):1000-1007.

153. Pickering TG, Shimbo D, Haas D: Ambulatory blood-pressure monitoring. N Engl J Med 2006, 354(22):2368-2374.

154. Agarwal R, Brim NJ, Mahenthiran J, Andersen MJ, Saha C: Out-ofhemodialysis-unit blood pressure is a superior determinant of left ventricular hypertrophy. Hypertension 2006, 47(1):62-68.

155. Agarwal R: Blood pressure and mortality among hemodialysis patients. Hypertension 2010, 55(3):762-768.

156. O'Brien E, Asmar R, Beilin L, Imai Y, Mancia G, Mengden T, Myers M, Padfield P, Palatini P, Parati $G$, et al: Practice guidelines of the European Society of Hypertension for clinic, ambulatory and self blood pressure measurement. J Hypertens 2005, 23(4):697-701.

157. Agarwal R, Andersen MJ, Bishu K, Saha C: Home blood pressure monitoring improves the diagnosis of hypertension in hemodialysis patients. Kidney Int 2006, 69(5):900-906.

158. Alborzi P, Patel N, Agarwal R: Home blood pressures are of greater prognostic value than hemodialysis unit recordings. Clin J Am Soc Nephrol 2007, 2(6):1228-1234.

159. Wan SH, Hart M, Hajjar I: A novel measurement index for antihypertensive medication burden and its use. Hypertension 2009, 54(5):e135-e136.

160. Thomson WM: Measuring change in dry-mouth symptoms over time using the Xerostomia Inventory. Gerodontology 2007, 24(1):30-35.

161. Thomson WM, Chalmers JM, Spencer AJ, Williams SM: The Xerostomia Inventory: a multi-item approach to measuring dry mouth. Community Dent Health 1999, 16(1):12-17.

162. Thomson WM, van der Putten GJ, de Baat C, Ikebe K, Matsuda K, Enoki K, Hopcraft MS, Ling GY: Shortening the xerostomia inventory. Oral Surg Oral Med Oral Pathol Oral Radiol Endod 2011, 112(3):322-327.

163. Bots CP, Brand HS, Veerman EC, Valentijn-Benz M, Van Amerongen BM, Valentijn RM, Vos PF, Bijlsma JA, Bezemer PD, Te Wee PM, et al: Interdialytic weight gain in patients on hemodialysis is associated with dry mouth and thirst. Kidney Int 2004, 66(4):1662-1668.

164. KDOQI: Clinical practice guidelines for cardiovascular disease in dialysis patients. Am J Kidney Dis 2005, 45:16-153.

165. Tomlinson LA: Methods for assessing arterial stiffness: technical considerations. Curr Opin Nephrol Hypertens 2012, 21(6):655-660.

166. Locatelli F, Di Filippo G, Manzoni C: Hemodialysis fliud composition. In Replacement of renal function by dialysis. 5th edition. Edited by Hörl WH, Koch KM, Lindsay RM, Ronco C, Winchester JF. Dordrecht, The Netherlands: Springer; 2004:585-587

167. Manns B, Johnson JA, Taub K, Mortis G, Ghali WA, Donaldson C: Quality of life in patients treated with hemodialysis or peritoneal dialysis: what are the important determinants? Clin Nephrol 2003, 60(5):341-351.

168. Manns BJ, Walsh MW, Culleton BF, Hemmelgarn B, Tonelli M, Schorr M, Klarenbach S, Alberta Kidney Disease N: Nocturnal hemodialysis does not improve overall measures of quality of life compared to conventional hemodialysis. Kidney Int 2009, 75(5):542-549.

169. Wyld M, Morton RL, Hayen A, Howard K, Webster AC: A systematic review and meta-analysis of utility-based quality of life in chronic kidney disease treatments. PLoS Med 2012, 9(9):e1001307.

170. Rao S, Carter WB, Mapes DL, Kallich JD, Kamberg CJ, Spritzer KL, Hays RD: Development of subscales from the symptoms/problems and effects of 
kidney disease scales of the kidney disease quality of life instrument. Clin Ther 2000, 22(9):1099-1111.

171. Kallich JD, Hays RD, Mapes DL, Coons SJ, Carter WB: The RAND kidney disease and quality of life instrument. Nephrol News Issues 1995, 9(9):29-36.

172. Hays RD, Kallich JD, Mapes DL, Coons SJ, Carter WB: Development of the kidney disease quality of life (KDQOL) instrument. Qual Life Res 1994, 3(5):329-338.

173. Dolan P: Modeling valuations for EuroQol health states. Med Care 1997, 35(11):1095-1108.

174. Patel RK, Jardine AG, Mark PB, Cunningham AF, Steedman T, Powell JR, McQuarrie EP, Stevens KK, Dargie HJ: Association of left atrial volume with mortality among ESRD patients with left ventricular hypertrophy referred for kidney transplantation. Am J Kidney Dis 2010, 55(6):1088-1096.

175. Mark PB, Patel RK, Jardine AG: Are we overestimating left ventricular abnormalities in end-stage renal disease? Nephrol Dial Transplant 2007, 22(7):1815-1819.

176. Pan W: Akaike's information criterion in generalized estimating equations. Biometrics 2001, 57(1):120-125.

177. Covic A, Goldsmith DJ, Georgescu G, Venning MC, Ackrill P:

Echocardiographic findings in long-term, long-hour hemodialysis patients. Clin Nephrol 1996, 45(2):104-110.

178. Huting J, Kramer W, Charra B, Laurent G, Wizemann V, Schutterle G: Asymmetric septal hypertrophy and left atrial dilatation in patients with end-stage renal disease on long-term hemodialysis. Clin Nephrol 1989, 32(6):276-283.

doi:10.1186/1471-2369-14-149

Cite this article as: Dunlop et al:: Rationale and design of the Sodium Lowering In Dialysate (SoLID) trial: a randomised controlled trial of low versus standard dialysate sodium concentration during hemodialysis for regression of left ventricular mass. BMC Nephrology 2013 14:149.

\section{Submit your next manuscript to BioMed Central and take full advantage of:}

- Convenient online submission

- Thorough peer review

- No space constraints or color figure charges

- Immediate publication on acceptance

- Inclusion in PubMed, CAS, Scopus and Google Scholar

- Research which is freely available for redistribution 